Sticky consumption and wealth effects in Switzerland Alain Galli

SNB Working Papers

$14 / 2016$ 


\section{Legal Issues}

\section{DISCLAIMER}

The views expressed in this paper are those of the author(s) and do not necessarily represent those of the Swiss National Bank. Working Papers describe research in progress. Their aim is to elicit comments and to further debate.

\section{COPYRIGHT@}

The Swiss National Bank (SNB) respects all third-party rights, in particular rights relating to works protected by copyright (information or data, wordings and depictions, to the extent that these are of an individual character).

SNB publications containing a reference to a copyright (@ Swiss National Bank/SNB, Zurich/year, or similar) may, under copyright law, only be used (reproduced, used via the internet, etc.) for non-commercial purposes and provided that the source is mentioned. Their use for commercial purposes is only permitted with the prior express consent of the SNB.

General information and data published without reference to a copyright may be used without mentioning the source. To the extent that the information and data clearly derive from outside sources, the users of such information and data are obliged to respect any existing copyrights and to obtain the right of use from the relevant outside source themselves.

\section{LIMITATION OF LIABILITY}

The SNB accepts no responsibility for any information it provides. Under no circumstances will it accept any liability for losses or damage which may result from the use of such information. This limitation of liability applies, in particular, to the topicality, accuracy, validity and availability of the information.

ISSN 1660-7716 (printed version)

ISSN 1660-7724 (online version)

(C) 2016 by Swiss National Bank, Börsenstrasse 15,

P.O. Box, $\mathrm{CH}-8022$ Zurich 


\title{
Sticky consumption and wealth effects in Switzerland*
}

\author{
Alain Galli \\ Swiss National Bank and University of Bern ${ }^{\dagger}$
}

September 8, 2016

\begin{abstract}
When assessing the effect of changes in wealth on household expenditures, most empirical studies have used cointegration-based approaches. These approaches rely on the existence of a stable long-run relationship among consumption, wealth and income. However, in Switzerland no such relationship seems to be present after 2001. Motivated by this issue, this paper applies a recently suggested approach to estimating long-run wealth effects on consumption that does not rely on cointegration. This new approach relies on sticky consumption growth, which can be motivated by consumption habits or sticky expectations. In both cases, long-run wealth effects are the result of short-run reactions of households to changes in wealth which become long-lasting. Using this methodology, the estimated wealth effects on consumption in Switzerland are larger than suggested by cointegration-based estimates. Furthermore, the results show that there seems to be a remarkably high degree of consumption stickiness in Switzerland.
\end{abstract}

JEL classification: D12, E21, E44, C22

Keywords: Wealth effects, consumption dynamics, habit formation, sticky expectations, Bayesian estimation

\footnotetext{
*I want to thank Gregor Bäurle, Matthias Lutz, Klaus Neusser, Rolf Scheufele, Jiri Slacalek, an anonymous referee and seminar participants at the 2015 OeNB-BuBa-SNB workshop in Vienna for their valuable comments. The views expressed in this paper are those of the author and not necessarily those of the Swiss National Bank.

${ }^{\dagger}$ Swiss National Bank, P.O. Box, Börsenstrasse 15, 8022 Zürich. E-Mail: alain.galli@snb.ch.
} 


\section{Introduction}

Changes in wealth can affect the expenditures of consumers in both the short-run and the long-run. When assessing such effects, i.e., the estimation of marginal propensities to consume (MPC) out of wealth, most empirical studies have used cointegration-based approaches. ${ }^{1}$ These approaches rely on the existence of a stable long-run relationship among consumption, wealth and income, which is motivated by linearizing and rewriting the intertemporal budget constraint of households. The resulting cointegrating residual, called cay, can be interpreted as an approximation of the consumption-to-wealth ratio. It is a function of the net present value of future net returns on aggregate wealth and future consumption growth. If these two variables are assumed to be stationary, the cay residual will be stationary and consumption, wealth and income will be cointegrated. The MPC out of wealth is then given by a transformation of the coefficient on wealth in the cointegrating vector of these three variables. Internationally, this MPC out of wealth usually lies between 3 and 7 cents. A good, broad survey of the literature on empirical evidence for wealth effects on consumption was performed by Cooper and Dynan (2014) for studies using macro data and those using micro data.

For Switzerland, the question of how changes in wealth affect household expenditures is particularly interesting today. Uptrends in stock market prices and the parallel rise in real estate prices have led to a strong increase in Swiss household wealth over the past few years. From 2004 to 2014, per capita wealth rose by almost 40\%. Despite the potential importance of wealth effects for Switzerland, hardly any studies have investigated this question. Only two studies, both cointegration-based, have appeared so far. The first one, Schmid (2013), estimated that a 1\% increase in wealth increases consumption expenditures by $0.42 \%$ in the long-run. This would correspond to a MPC out of wealth of approximately 5.7 Swiss centime, suggesting that a one-franc increase in Swiss household wealth would cause an increase of 5.7 Swiss centime in consumption expenditures in the long-run. The second study, Galli (2016), updated these estimates based on more recent and revised data. The results for the entire sample period, 1980-2012, suggested that wealth effects were hardly present in Switzerland. However, this result turned out to be largely driven by the most recent past, during which consumption did not respond to several major changes in wealth. Until 2001, in contrast, consumption, wealth and income were found to be

\footnotetext{
${ }^{1}$ See, e.g., Lettau and Ludvigson (2001), Lettau and Ludvigson (2004), Benjamin, Chinloy, and Jud (2004), Hamburg, Hoffmann, and Keller (2008), Sousa (2010) or Fisher and Voss (2004).
} 
cointegrated with an MPC out of wealth that was in the range of 2.0 to 4.8 Swiss centime.

This unstable outcome may be due to several fragility issues related to the cointegrationbased approach to estimating wealth effects. Motivated by the drawbacks of the cointegration approach, Slacalek (2009) and Carroll, Otsuka, and Slacalek (2011) recently proposed an alternative approach to estimating long-run wealth effects on consumption that does not require the existence of a stable long-run relationship. Instead, the method relies on sticky consumption growth, which can be motivated by consumption habits or sticky expectations. In both cases, the long-run wealth effect is then the accumulation of short-run reactions of households to a change in wealth. The higher the degree of stickiness, the longer the period over which a change in wealth affects household expenditures. International empirical evidence of sticky consumption growth can be found in, e.g., Carroll, Slacalek, and Sommer (2011). Compared to the cointegration method, the consumption stickiness-based approach to estimating wealth effects has the advantage of being much more robust to changes in the underlying parameters, including expected income growth and demographics, as Carroll, Otsuka, and Slacalek (2011) argued. Furthermore, in contrast to the cointegration-based approach, estimating separate financial and housing wealth effects is straightforward.

This paper applies this alternative, consumption stickiness-based approach to Swiss data and investigates how the results compare to those obtained in cointegration-based studies. Furthermore, by distinguishing between financial and non-financial wealth, this paper also tries to shed light on how the recent strong rise in real estate prices and housing wealth could affect personal consumption expenditures. Possible differences in the strength of households' reaction to changes in financial wealth and changes in housing wealth were previously discussed in Galli (2016).

The obtained results reveal four things: First, there seems to be a remarkably high degree of consumption stickiness in Switzerland. Viewed in a sticky expectations context, only approximately half of the households update their expectations and optimize their consumption behavior in a given year. Therefore, consumption growth is quite persistent even on an annual basis.

Second, wealth effects in Switzerland are substantially larger (between 5.7 and 7.4 Swiss centime at the median) than indicated by the cointegration-based results of Galli (2016), which suggested - driven by the data sample after 2001 - that wealth effects are hardly present. Thus, changes in wealth do have a long-run effect on consumption in 
Switzerland, but a stable level-relationship between consumption and wealth no longer seems to exist. This also implies the absence of error-correction mechanisms.

Third, the results for separate financial and housing wealth effects suggest that the median one-period MPC somewhat higher out of financial wealth than out of total wealth, and the one out of housing wealth is somewhat smaller. In addition, there is a much higher degree of uncertainty surrounding the latter.

Fourth, a comparison with estimates for other countries reveals that the degree of stickiness in Swiss private consumption is among the highest. Furthermore, in terms of wealth effects, the short-run wealth effect is rather small compared to other countries. However, given the high degree of stickiness of Swiss private consumption, changes in wealth in a given period have an effect on consumption not only in the next period but also, to large extent, in upcoming periods. Thus, the accumulated long-run effect lies somewhere in the middle of the international results. The same applies to the separate financial and housing wealth effects.

The remainder of this paper is organized as follows: Section 2 provides an overview of the theoretical motivation behind the stickiness-based approach to estimating wealth effects. Section 3 describes the estimation strategy and the data. Section 4 presents the empirical results for the case of Switzerland and shows how these results compare to international results. Section 5 concludes the paper. 


\section{Theoretical motivation}

Wealth effecs are often estimated using cointegration-based approaches, which rely on the existence of a stable relationship among consumption, wealth and income. In the Swiss case, however, no such relationship seems to have been present since 2001 (see Galli, 2016). Several studies, such as Slacalek (2009) and Carroll, Otsuka, and Slacalek (2011), have shown that the cointegration approach to estimating wealth effects is generally fraught with fragility issues related to changes in the fundamentals of the economy, such as the long-run growth rate, the long-run interest rate, tax and pension schemes, social security generosity or demographics, which affect the equilibrium among consumption, wealth and income and thus the cointegrating vector. Labor frictions and income uncertainty may also affect the results. The authors further argued that due to changes in factors that affect the economy, one would need very long data series to obtain reliable estimates of the cointegrating vector.

Muellbauer (2007) and Aron, Muellbauer, and Murphy (2008) issued related critiques. They also questioned the reliability of estimated wealth effects because estimation results are often affected by (omitted) changes in fundamentals. For instance, when estimating both housing wealth effects and total wealth effects, controls for common drivers of house prices and consumption, such as income growth expectations, interest rates, credit supply conditions, indicators of income uncertainty or even income itself, are often omitted. The authors argued in particular that when not controlling for the direct effect of credit liberalization, housing wealth effects can be over-estimated because "a major part of the rise of the consumption to income ratio was due to easing of credit availability" (p. 28)..$^{2}$

Aron, Duca, Muellbauer, Murata, and Murphy (2011) showed that when controlling for such changes in credit conditions and additionally using a more disaggregate wealth vector, the relationship among consumption, wealth and income can become stable over time again and the cointegration approach remains valid. However, this is not the case for Switzerland.

Motivated by the mentioned issues regarding the effect of structural changes on cointegration-based estimates for wealth effects, Slacalek (2009) and Carroll, Otsuka, and

\footnotetext{
${ }^{2}$ In principle, this omitted variable problem may arise not only when using cointegration-based approaches to estimating wealth effects but also in general. However, regime changes can have a lager influence in the cointegration context because they may lead to a violation of the underlying assumption of a stable relationship among consumption, wealth and income.
} 
Slacalek (2011) recently proposed an approach to estimating wealth effects on consumption that does not require the existence of a stable long-run relationship. Instead, the method assumes sticky consumption growth, which can be motivated by consumption habits or sticky expectations. In both cases, the long-run wealth effect is then the accumulation of households' short-run reactions to changes in wealth.

\subsection{General model of sticky consumption growth}

Theoretically, as described in Sommer (2007), such consumption stickiness can be motivated in two ways: consumption habits or sticky expectations. In a habit formation model, households maximize utility as follows:

$$
\begin{aligned}
& \max _{C_{t}} \sum_{t=0}^{\infty} B^{t} U\left[C_{t}-\mathcal{X} C_{t-1}\right]=\max _{C_{t}} \sum_{t=0}^{\infty} B^{t} U\left[(1-\mathcal{X}) C_{t}+\mathcal{X} \Delta C_{t}\right] \\
& \text { s.t. } A_{t+1}=(1+r)\left(A_{t}+Y_{t}-C_{t}\right)
\end{aligned}
$$

$B$ is a discount factor, $\mathcal{X}$ is the degree of stickiness in consumption, $1+r$ is the gross interest rate, $A_{t}$ is total wealth, $Y_{t}$ is income and $C_{t}$ is the level of consumption. In this framework, utility comes from both the level of consumption in period $t$ and from the change in consumption between $t-1$ and $t$. Thus, in a habit formation context, habits are irrelevant if $\mathcal{X}=0$; therefore, utility only comes from the level of consumption in period t. At the other extreme, in case of $\mathcal{X}=1$, the level of consumption itself is not relevant, and utility is only derived from increases in the level of consumption.

Assuming a standard CRRA utility function, the optimization problem of the household is given by

$$
\max E_{t}\left[\sum_{t=0}^{T} B^{t} \frac{X_{t}^{1-\sigma}}{1-\sigma}\right],
$$

where $X$ is the utility-generating object. This yields the following well-known Euler equation:

$$
E\left[(1+r) B\left(\frac{X_{t+1}}{X_{t}}\right)^{-\sigma}\right]=1 .
$$

Assuming rational expectations, the expectation of utility-generating object $X$ equals its actual realization plus an expectational error. Thus, we have

$$
(1+r) B\left(\frac{X_{t+1}}{X_{t}}\right)^{-\sigma}=1+e_{t+1}
$$


where $e_{t+1}$ is a mean-zero forecast error. Under rational expectations, we have $E_{t}\left[e_{t+1}\right]=0$ and $\operatorname{Cov}\left(e_{t}, e_{t+1}\right)=0$. Taking logs and rewriting the equation yields

$$
\Delta \log \left(X_{t+1}\right)=\frac{1}{\sigma}[\log (B)+\log (1+r)]-\frac{1}{\sigma} \log \left(1+e_{t+1}\right)
$$

After replacing $X_{t}$ with our utility relevant consumption term, $C_{t}-\mathcal{X} C_{t-1}$, we have

$$
\Delta \log \left(C_{t+1}-\mathcal{X} C_{t}\right)=\frac{1}{\sigma}[\log (B)+\log (1+r)]-\frac{1}{\sigma} \log \left(1+e_{t+1}\right) .
$$

Following Muellbauer (1988) and Dynan (2000), the left hand side of this equation can be approximated by $\Delta \log \left(C_{t+1}\right)-\mathcal{X} \Delta \log \left(C_{t}\right)$. Thus, we obtain the following approximation for the result of the dynamic optimization problem:

$$
\Delta \log C_{t}=\mu+\mathcal{X} \Delta \log C_{t-1}+\varepsilon_{t} \text { where } \varepsilon_{t} \sim N\left(0, \sigma_{\varepsilon}^{2}\right)
$$

$\mu$ captures all constant terms, and $\varepsilon_{t}$ is an error term that represents innovations to lifetime resources, as described in Sommer (2007). The equation states that the log change in aggregate consumption approximately follows an $\mathrm{AR}(1)$ process.

The same outcome can be obtained from a sticky expectations framework, in which we can rewrite aggregate consumption as follows:

$$
C_{t}=\int_{0}^{1} c_{t, i} d i=\mathcal{X} C_{t-1}+(1-\mathcal{X}) \int_{\text {updaters }} c_{t, i}=\mathcal{X} C_{t-1}+(1-\mathcal{X}) C_{t}^{\text {updaters }}
$$

$c_{t, i}$ is the consumption of household $i$ at time $t$, and $1-\mathcal{X}$ is the fraction of the households that update their expectations in the given period and reoptimize their consumption, the updaters. The remaining households, the non-updaters, just consume their last period amount of consumption.

Taking first differences of this equation results in

$$
\Delta C_{t}=\mathcal{X} \Delta C_{t-1}+(1-\mathcal{X}) \Delta C_{t}^{\text {updaters }}
$$

Thus, the change in aggregate consumption is a weighted sum of the changes in total consumption of the nonupdaters and the updaters. Carroll and Slacalek (2006) showed that the term related to the updaters is approximately mean zero and iiid. Therefore, as in the habit formation framework, we find that the change in consumption follows an 
$\operatorname{AR}(1)$ process.

However, it is important to note that this is the case only when consumption is observed at the same frequency as consumption decisions are made. When consumption is observed at a quarterly frequency but consumption decisions are made on a monthly basis, time-aggregation restrictions change this process so that the log change in aggregated consumption growth approximately follows an $\operatorname{ARMA}(1,2)$ process of the form

$$
\Delta \log C_{t}=\mu+\mathcal{X} \Delta \log C_{t-1}+\varepsilon_{t}+\lambda_{1}(\mathcal{X}) \varepsilon_{t-1}+\lambda_{2}(\mathcal{X}) \varepsilon_{t-2}
$$

where $\lambda_{1}$ and $\lambda_{2}$ are complicated functions of $\mathcal{X}^{3}$

\subsection{Accounting for measurement error in consumption}

As Sommer (2007) and Carroll, Otsuka, and Slacalek (2011) noted, measured consumption $C_{t}^{o b s}$, as published in the official national accounts, can include three types of noise that are not incorporated in the consumption stickiness theory: sampling measurement errors (small sample problems) $u^{s}$, non-sampling measurement errors (imputation of data) $u^{n s}$ and transitory elements (e.g., weather effects) $u^{t r}$. Due to this noise, measured consumption $C_{t}^{o b s}$ does not equal true (i.e., fundamental) consumption $C_{t}$ in the short-run:

$$
\log C_{t}^{o b s}=\log C_{t}+\underbrace{u_{t}^{s}+u_{t}^{n s}+u_{t}^{t r}}_{\equiv u_{t}} \Rightarrow \Delta \log C_{t}=\Delta \log C_{t}^{o b s}-\Delta u_{t}
$$

Therefore, written in terms of measured consumption growth, equation (8) changes to

$$
\Delta \log C_{t}^{o b s}=\mu+\mathcal{X} \Delta \log C_{t-1}^{o b s}+\varepsilon_{t}+u_{t}-(1+\mathcal{X}) u_{t-1}+\mathcal{X} u_{t-2} .
$$

\subsection{Wealth effects under sticky consumption growth}

As we will observe in this section, the degree of stickiness in consumption, $\mathcal{X}$, determines the extent to which short-run effects of wealth changes on consumption also remain effective in the future and thus become long-lasting. In the presence of sticky expectations or habit formation, changes in household wealth in period t affect growth of private consumption expenditures not only in the contemporaneous period but also in the upcoming

\footnotetext{
${ }^{3}$ Sommer (2007) showed that the relationship between $\lambda_{1}, \lambda_{1}$ and $\mathcal{X}$ is given by $\frac{\lambda_{1}\left(1+\lambda_{2}\right)}{1+\lambda_{1}^{2}+\lambda_{2}^{2}}=$ $\frac{4+\mathcal{X}^{\frac{1}{3}}\left(11+\mathcal{X}^{\frac{1}{3}}\left(20+\mathcal{X}^{\frac{1}{3}}\left(11+4 \mathcal{X}^{\frac{1}{3}}\right)\right)\right)}{19+\mathcal{X}^{\frac{1}{3}}\left(32+\mathcal{X}^{\frac{1}{3}}\left(39+\mathcal{X}^{\frac{1}{3}}\left(32+19 \mathcal{X}^{\frac{1}{3}}\right)\right)\right)}$ and $\frac{\lambda_{2}}{1+\lambda_{1}^{2}+\lambda_{2}^{2}}=\frac{\mathcal{X}^{\frac{2}{3}}}{19+\mathcal{X}^{\frac{1}{3}}\left(32+\mathcal{X}^{\frac{1}{3}}\left(39+\mathcal{X}^{\frac{1}{3}}\left(32+19 \mathcal{X}^{\frac{1}{3}}\right)\right)\right)}$. The author points out that the MA parameters take values of $\lambda_{1} \approx 0.4$ and $\lambda_{2} \approx 0$ for $\mathcal{X}>0.3$
} 
Figure 1: MPCs per quarter and cumulative MPC with different degrees of consumption stickiness
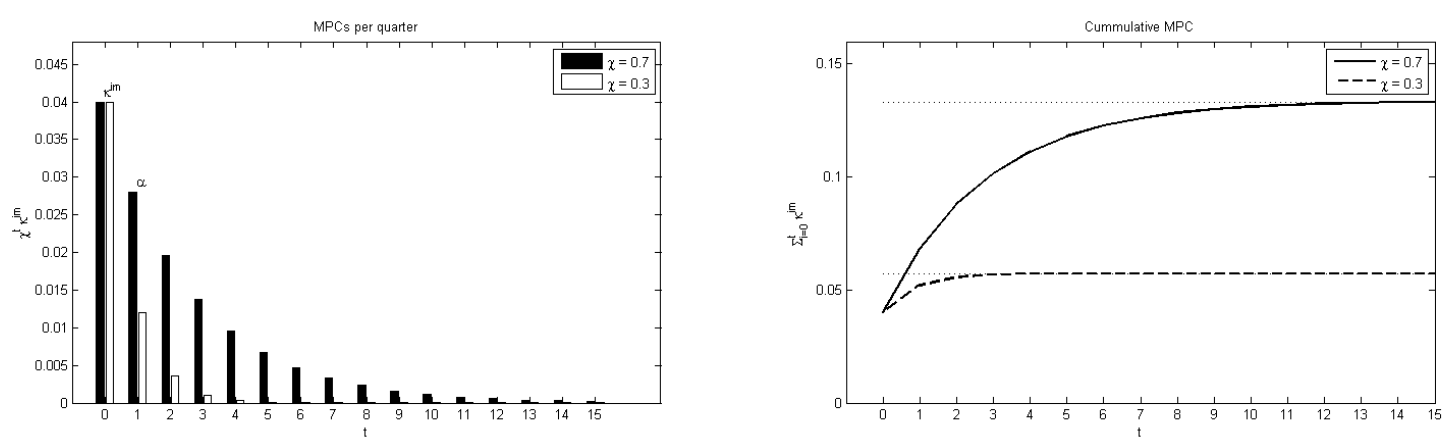

Given an immediate MPC $\kappa^{i m}=0.04$, the left panel shows the reactions of consumption growth in period $t$ to a one unit change in wealth in period 0 with $\mathcal{X}=0.3$ (black bars) and $\mathcal{X}=0.7$ (white bars). The right panel shows the corresponding cumulative responses. The dotted horizontal lines represent the long-run wealth effects.

periods. The degree of persistence depends on the amount of stickiness in consumption.

We define the immediate, i.e., contemporaneous, MPC out of wealth by $\kappa^{i m}$. The cumulative long-run MPC out of total wealth $\kappa$ (Carroll, Otsuka, and Slacalek (2011) call the latter the "eventual" MPC) is then given by

$$
\kappa=\underbrace{\kappa^{i m}}_{t=0}+\underbrace{\mathcal{X} \kappa^{i m}}_{t=1}+\underbrace{\mathcal{X} \kappa^{i m}{ }^{2}}_{t=2}+\underbrace{\mathcal{X} \kappa^{i m^{3}}}_{t=3}+\underbrace{\mathcal{X} \kappa^{i m^{4}}}_{t=4}+\underbrace{\ldots}_{t>4}=\sum_{i=0}^{\infty} \mathcal{X}^{i} \kappa^{i m}
$$

Applying the infinite horizon formula yields

$$
\kappa=\frac{\kappa^{i m}}{1-\mathcal{X}}
$$

Therefore, the stickier consumption, the larger the effect of a change in aggregate household wealth on household expenditures in the long-run. This is visualized in Figure 1 with two different degrees of stickiness. With a fairly high consumption stickiness of 0.7 , the immediate wealth effect $\kappa^{i m}=0.04$ remains partially effective for a comparatively long period and the long-run MPC out of wealth accumulates to 0.133. In contrast, with a rather low consumption stickiness of 0.3 , the immediate wealth effect of 0.04 vanishes fairly quickly, with a long-run wealth effect of only 0.057 , less than half that under high consumption stickiness.

Equation (15) suggests that an estimate for the long-run wealth effect $\kappa$ can be directly obtained from estimates on consumption stickiness parameter $\mathcal{X}$ and immediate wealth effect $\kappa^{i m}$. To estimate the latter, we cannot directly regress the change in 
consumption in period $t$ on the contemporaneous change in wealth since wealth is an end-of-period stock measure. However, when consumption is assumed to follow an autoregressive process, the immediate wealth effect can be obtained (see Carroll, Otsuka, and Slacalek, 2011) by a transformation of the form

$$
\kappa^{i m}=\frac{\alpha}{\mathcal{X}}
$$

where $\alpha=\mathcal{X} \kappa^{i m}$ is the one-period wealth effect that represents the effect of a change in wealth in a given period on consumption in the next period. An estimate for $\alpha$ can then be obtained by a regression of the form

$$
\Delta \log C_{t}=\text { const }+\tilde{\alpha} \Delta \log A_{t-1}+\tilde{v}_{t}
$$

where $A$ represents asset wealth, i.e., financial and housing wealth, and $\tilde{v}$ is an error-term. However, since this equation is in terms of log-differences, $\tilde{\alpha}$ is an elasticity rather than the MPC out of total wealth, which is usually considered when assessing wealth effects. Carroll, Otsuka, and Slacalek (2011) proposed a simple solution to obtain a direct estimate of the MPC by using the ratio of the absolute changes in wealth and consumption relative to an initial level of consumption rather than log changes in wealth and consumption. These new variables are defined as follows: $\partial C_{t} \equiv\left(C_{t}-C_{t-1}\right) / C_{t-2}$ and $\partial A_{t-1} \equiv\left(A_{t-1}-\right.$ $\left.A_{t-2}\right) / C_{t-2}$. The regression equation then changes to

$$
\partial C_{t}=\text { const }+\alpha \partial A_{t-1}+v_{t} \text { where } v_{t} \sim N\left(0, \sigma_{v}^{2}\right)
$$

Thus, if wealth increases by one unit in a given period, consumption will increase by $\alpha$ units in the next period.

As we will observe in section 4 , the estimated coefficients are somewhat sensitive to the choice of instrument. Therefore, we follow Carroll, Otsuka, and Slacalek (2011) and adjust the wealth measure slightly, accounting for the fact that today's consumption can also be influenced by wealth changes in periods before $\mathrm{t}-1 \mathrm{:}^{4}$

$$
\Delta C_{t}^{o b s} \approx \alpha \Delta A_{t-1}+\mathcal{X} \alpha \Delta A_{t-2}+v_{t}=\kappa^{i m} \mathcal{X}\left(\Delta A_{t-1}+\mathcal{X} \Delta A_{t-2}\right)+v_{t}
$$

\footnotetext{
${ }^{4}$ Because the calculations in this study are based on annual rather than quarterly data, adding one further lag should be enough.
} 
On that basis, the regression-relevant transformation for wealth changes to

$$
\bar{\partial} A_{t-1}=\left(\Delta A_{t-1}+\mathcal{X} \Delta A_{t-2}\right) / C_{t-2}^{o b s} .
$$

and equation (18) involving the one-period MPC out of total wealth, $\alpha$, changes to

$$
\partial C_{t}^{o b s}=\text { const }+\alpha \bar{\partial} A_{t-1}+v_{t} \text { where } v_{t} \sim N\left(0, \sigma_{v}^{2}\right) .
$$

Estimating $\alpha$ with this wealth measure should increase precision.

Using the estimate on $\alpha$, the computation of the long-run wealth effect is then given by replacing the immediate effect by the one-quarter wealth effect in equation (15), so that

$$
\kappa=\frac{\kappa^{i m}}{1-\mathcal{X}}=\frac{\frac{1}{\mathcal{X}} \alpha}{1-\mathcal{X}}=\frac{\alpha}{\mathcal{X}(1-\mathcal{X})}
$$

Our focus is not only on the effect of changes in total wealth on consumption but also on the separate effects of changes in financial and housing wealth. To estimate separate MPCs out of financial and housing wealth, the approach of Carroll, Otsuka, and Slacalek (2011) can easily be adapted by adjusting equation (18) to

$$
\partial C_{t}=\text { const }+\alpha^{f} \partial A_{t-1}^{f}+\alpha^{h} \partial A_{t-1}^{h}+v_{t},
$$

where $A^{f}$ represents financial wealth and $A^{h}$ (net) housing wealth.

The one-period MPCs out of financial and housing wealth are $\alpha^{f}$ and $\alpha^{h}$, and the long-run MPCs can be calculated as

$$
\kappa^{f}=\frac{\alpha^{f}}{\mathcal{X}(1-\mathcal{X})}, \kappa^{h}=\frac{\alpha^{h}}{\mathcal{X}(1-\mathcal{X})} .
$$

For a detailed discussion on the potential of housing wealth effects in Switzerland, see Galli (2016). 


\section{Estimation strategy and data}

In this section, the consumption stickiness-based approach to estimating wealth effects is applied for the case of Switzerland. In contrast to Carroll, Otsuka, and Slacalek (2011) and Slacalek (2009), who solely relied on IV regressions, as a cross-check this study additionally uses a Kalman filter technique to estimate the stickiness parameter to avoid over-relying on the choice of instruments.

I also make use of Bayesian inference, which seems attractive in this framework. First, this allows the inclusion of theoretically or empirically motivated beliefs on the degree of consumption stickiness and the magnitude of wealth effects through the choice of priors. For example, one possibly wants to ensure that the estimated autoregressive process for consumption growth is stationary, using a prior on $\mathcal{X}$ which is restricted to lying between zero and one. Another example would be to center the priors on the MPCs around the estimation results from cointegration estimates or other countries. Second, by using Bayesian estimation techniques, we easily obtain distributions for the estimated wealth effects instead of only point estimates and the corresponding standard errors in frequentist inference. This permits a more detailed analysis of the degree and symmetry of uncertainty surrounding the estimated MPCs (although this also depends on the distributional assumptions). Third, as highlighted in Kim and Nelson (1999), when estimating state space models using Bayesian estimation, inferences on the states are not conditional on the estimated values of the hyperparameters but based on the joint distribution of the state variable and the hyperparameters. This will be of interest in section 3.1.2, where the degree of stickiness in consumption and the path of true consumption over time are estimated using the Kalman Filter approach. Furthermore, compared to the Maximum Likelihood estimation of a state space model, the task of finding appropriate starting values often also becomes less challenging.

To estimate the parameters of interest - the consumption stickiness parameter $\mathcal{X}$, short-run wealth effects $\kappa^{i m}$ and $\alpha$, and eventually the ultimate object of interest, the long-run MPC $\kappa$ - we make use of the fact that the two parameters $\alpha$ and $\mathcal{X}$, or, in general, models (8) and (18), can be estimated independently. This is because for each equation, the data likelihood is independent when the two error-terms, $\varepsilon$ and $v$, as well as the priors are independent. 


\subsection{Estimation of the consumption stickiness parameter}

To estimate the consumption stickiness parameter, we can use only data on observed consumption $C_{t}^{o b s}$ because true consumption $C_{t}$ is unobserved. However, because observed consumption contains measurement error (as discussed in section 2.2), estimating equation (13) by ordinary least squares would yield an inconsistent estimate of $\mathcal{X}$, since $\operatorname{Cov}\left[\Delta \log C_{t-1}, \varepsilon_{t}+u_{t}-(1+\mathcal{X}) u_{t-1}+\mathcal{X} u_{t-2}\right] \neq 0$, i.e., the independent variable is correlated with the error-term. Sommer (2007) proposed two ways to attack this issue: an instrumental variables estimation (IV) or a Kalman filter approach (KF). Both account for measurement error, either by using adequate instruments (IV) or by explicitly modeling the measurement error-component (KF).

\subsubsection{A Bayesian instrumental variable approach}

One solution to overcome the problem of the correlation between the independent variables and the error-term is to estimate equation (13) with an instrumental variable approach. This requires finding adequate instruments that are correlated with true consumption but not with the measurement errors. Carroll, Otsuka, and Slacalek (2011) proposed lagged wealth, plus possibly the nominal interest rate and consumer expectations on unemployment as instruments. Other common instruments are disposable income or compensation of employees.

As it turns out, finding good instruments is rather difficult for Swiss private consumption. They either show little or no correlation with consumption (e.g., interest rates), or the time series is not long enough (e.g., consumer expectations on unemployment). Apart from lagged wealth, the only remaining straightforward variables are the consumer sentiment index and lagged disposable income. ${ }^{5}$

To estimate by instrumental variables within a Bayesian framework, we follow Kleibergen and Zivot (2003), Rossi, Allenby, and McCulloch (2005), and, in particular, Cogley and Startz (2012). Applying their approach to the present framework, the structural equation is given by $\partial C_{t}=\mathcal{X} \partial C_{t-1}+\varepsilon_{t}$, or in matrix notation

$$
\partial C^{o b s}=\mathcal{X} \partial C_{-1}^{o b s}+\varepsilon
$$

\footnotetext{
${ }^{5}$ For disposable income, an endogeneity problem can arise since it comes from the same source as the dependent variable (national accounts) so that the measurements can be correlated. Lagging disposable income by one period should help reduce this problem.
} 
In a two-stage style using instrument(s) $\mathrm{Z}$, the first-stage equation is given by $\partial C_{t-1}^{o b s}=$ $\gamma Z_{t-2}+v_{t}$ or in matrix notation

$$
\partial C_{-1}^{o b s}=Z \gamma+v
$$

Substituting the first-stage equation into the structural equation yields the second-stage equation (also known as restricted reduced form):

$$
\partial C^{o b s}=Z_{\gamma} \mathcal{X}+\varepsilon+v \mathcal{X}
$$

Putting the last two equations in a seemingly-unrelated regression form, we obtain

$$
\left[\begin{array}{c}
\partial C^{o b s} \\
\partial C_{-1}^{o b s}
\end{array}\right]=\left[\begin{array}{cc}
Z & 0 \\
0 & Z
\end{array}\right]\left[\begin{array}{c}
\gamma \mathcal{X} \\
\gamma
\end{array}\right]+\underbrace{\left[\begin{array}{c}
\varepsilon+\mathcal{X} v \\
v
\end{array}\right]}_{\equiv w},
$$

with $w_{t} \sim \operatorname{iidN}\left(0, \Sigma_{w}\right)$.

In terms of priors, we use a normal prior for the consumption stickiness parameter $\mathcal{X}$ with mean $\underline{\mathcal{X}}=0$, variance $\underline{V}_{\mathcal{X}}$ and a truncation on the restricted region $(0,1)$. By doing so, we ensure that the autoregressive process of consumption growth is stationary and the autoregression coefficient is positive. For the instrument coefficient vector, $\gamma$, we use a normal prior with mean vector $\underline{\gamma}=0$ and diagonal covariance matrix $\underline{V}_{\gamma}$. For $\Sigma_{w}$ we use an inverse Wishart prior with scale matrix $\underline{S}$ and degrees of freedom $\underline{D F}$. The particular forms of these priors are chosen so that all conditional posterior distributions of the parameters are of known forms. This allows working with the Gibbs sampler as sampling technique for approximating the marginal posterior distributions of the parameters. These are obtained by closely following Cogley and Startz (2012). Details on the sampling procedure can be found in the appendix.

\subsubsection{A Bayesian Kalman filter approach}

The difficulty of finding good instruments in our context increases the likelihood of experiencing a weak-instrument problem. Therefore, stickiness parameter $\mathcal{X}$ is alternatively estimated by explicitly modeling the measurement error and setting up a state space system. The two underlying equations are (8) and (12), or (11) and (12) when consumption decisions are made at a lower frequency than consumption is observed. 
The state space form system for the more general case, where consumption decisions are made on a monthly basis and consumption is observed at a quarterly frequency, is represented by measurement equation

$$
\Delta \log C_{t}^{o b s}=\left[\begin{array}{lllll}
1 & 0 & 1 & 0 & 0
\end{array}\right]\left[\begin{array}{c}
\Delta \log C_{t} \\
-u_{t} \\
\Delta u_{t} \\
\varepsilon_{t} \\
\varepsilon_{t-1}
\end{array}\right]
$$

and transition equation

$$
\underbrace{\left[\begin{array}{c}
\Delta \log C_{t} \\
-u_{t} \\
\Delta u_{t} \\
\varepsilon_{t} \\
\varepsilon_{t-1}
\end{array}\right]}_{\beta_{t}}=\left[\begin{array}{ccccc}
\mathcal{X} & 0 & 0 & \lambda_{1}(\mathcal{X}) & \lambda_{2}(\mathcal{X}) \\
0 & 0 & 0 & 0 & 0 \\
0 & 1 & 0 & 0 & 0 \\
0 & 0 & 0 & 0 & 0 \\
0 & 0 & 0 & 1 & 0
\end{array}\right] \underbrace{\left[\begin{array}{c}
\Delta \log C_{t-1} \\
-u_{t-1} \\
\Delta u_{t-1} \\
\varepsilon_{t-1} \\
\varepsilon_{t-2}
\end{array}\right]}_{\beta_{t-1}}+\left[\begin{array}{c}
\varepsilon_{t} \\
-u_{t} \\
u_{t} \\
\varepsilon_{t} \\
0
\end{array}\right]
$$

with

$$
Q=\left[\begin{array}{ccccc}
\sigma_{\varepsilon}^{2} & 0 & 0 & \sigma_{\varepsilon}^{2} & 0 \\
0 & \sigma_{u}^{2} & -\sigma_{u}^{2} & 0 & 0 \\
0 & -\sigma_{u}^{2} & \sigma_{u}^{2} & 0 & 0 \\
\sigma_{\varepsilon}^{2} & 0 & 0 & \sigma_{\varepsilon}^{2} & 0 \\
0 & 0 & 0 & 0 & 0
\end{array}\right]
$$

If consumption decisions are made at the same frequency as consumption is observed, the estimation setup still applies after setting $\lambda_{1}=\lambda_{2}=0$. For Switzerland, initial maximum likelihood estimates indicate that $\mathcal{X}$ depends only to a negligible extent on the inclusion of lagged terms of $\varepsilon$, which suggests that consumption decisions are made at a lower than monthly frequency. Therefore, to be able to compute $\kappa$ in a simplified manner, this is assumed in the remainder of this paper.

In terms of priors, we use a normal prior for $\mathcal{X}$, which is given by $\mathcal{X} \sim N\left[\underline{\mathcal{X}}=0, \underline{V_{\mathcal{X}}}\right]$, again truncated on the restricted region $(0,1)$. The prior for $\sigma_{\varepsilon}^{2}$ is given by $\sigma_{\varepsilon}^{2} \mid \mathcal{X} \sim$ $I G\left[\frac{d_{1}}{2}, \frac{d_{2}}{2}\right]{ }^{6}$ The prior for $\sigma_{u}^{2}$ is given by $\sigma_{u}^{2} \sim I G\left[\frac{d_{3}}{2}, \frac{d_{4}}{2}\right]$. As before, the particular forms

\footnotetext{
${ }^{6}$ One could also rewrite the prior and posterior as an inverse Wishart distribution so that $\sigma_{\varepsilon}^{2} \mid \mathcal{X} \sim$
} 
of these priors are chosen so that all conditional posterior distributions of the parameters are of known forms. This allows working with the Gibbs sampler as sampling technique for approximating the marginal posterior distributions of the parameters. For the state space setup, these are obtained following Kim and Nelson (1999). Details on the sampling procedure can be found in the appendix.

\subsection{Estimation of the short- and long-run wealth effect on consumption}

The marginal posterior distribution of the one-period MPC out of total wealth $\alpha$ is obtained estimating equation (18) using observed consumption $C_{t}^{o b s}$, adding an additional step to the Gibbs sampling procedure from section 3.1.1 or 3.1.2, respectively. We use a normal prior for $\alpha$ with mean $\underline{\alpha}=0$ and variance $\underline{V_{\alpha}}$ and an inverse gamma prior for $\sigma_{v}^{2}$ with scale parameter $\underline{\theta}$ and degrees of freedom $\underline{T}$.

Following Koop (2003) or Lancaster (2004), to sample from $p\left(\sigma_{v}^{2} \mid \alpha\right)$, we make use of the fact that when $\alpha$ is assumed to be known, the conditional distribution of $\sigma_{v}^{2}$ is inverse gamma and is given by

$$
\sigma_{v}^{2} \mid \alpha \sim I G\left(\bar{T}=\underline{T}+T, \bar{\theta}=\underline{\theta}+\left(C-\partial A_{-1} \alpha\right)^{\prime}\left(C-\partial A_{-1} \alpha\right)\right) .
$$

To sample from $p\left(\alpha \mid \sigma^{2}\right)$, we make use of the fact that when $\sigma_{v}^{2}$ is known, the conditional distribution of $\alpha$ is normal and given by

$$
\alpha \mid \sigma_{v}^{2} \sim N\left(\bar{\alpha}=\bar{V}_{\alpha}\left(\underline{V}_{\alpha}^{-1} \underline{\alpha}+\frac{1}{\sigma_{v}^{2}} \partial A_{-1}^{\prime} \partial C_{t}\right), \bar{V}_{\alpha}=\left(\underline{V}_{\alpha}^{-1}+\frac{1}{\sigma_{v}^{2}} \partial A_{-1}^{\prime} \partial A_{-1}\right)^{-1}\right) .
$$

By replacing $\partial A_{-1}^{\prime} \partial C_{t}$ with $\partial A_{-1}^{\prime} \partial A_{-1} \alpha^{\text {ols }}$, we see that the conditional posterior mean of $\alpha$ is a weighted average of the prior mean $\underline{\alpha}$ and the OLS estimate $\alpha^{\text {ols }}$. To obtain approximate marginal distributions of the one-period MPC of wealth, $\alpha$ and $\sigma_{v}^{2}$, we add the draws from the corresponding conditional posteriors to the Gibbs sampling procedure.

Next, the contemporaneous MPC out of total wealth, $\kappa^{i m}$, is calculated according to equation (16). Since we assume $\mathcal{X}$ and $\alpha$ to be independent of each other, the posterior distribution of the contemporaneous wealth effect, $p\left(\kappa^{i m} \mid \mathcal{X}, \alpha\right)$, is obtained by calculating $\kappa^{i m}=\frac{\alpha}{\mathcal{X}}$ for each draw of $(\mathcal{X}, \alpha)$ from the Gibbs sampling procedure. The prior for $\kappa^{i m}$ is implicitly given by the priors on $\mathcal{X}$ and $\alpha$.

Finally, the marginal posterior distribution of the eventual wealth effect of con-

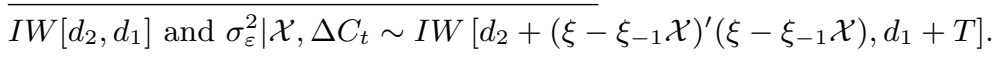


sumption, $p(\kappa \mid \mathcal{X}, \alpha)$, follows directly from equation (22) and is obtained similarly to the posterior for the contemporaneous wealth effect, calculating $\kappa=\frac{\alpha}{\mathcal{X}(1-\mathcal{X})}$ for each draw of $(\mathcal{X}, \alpha)$. The prior for $\kappa$ is implicitly given by the priors on $\mathcal{X}$ and $\alpha$.

\subsection{Data}

The Swiss data set is the same as that in Galli (2016) and covers the period 1981-2012. ${ }^{7}$ Both consumption and wealth are used in real per capita terms. Data on all measures of consumption (total, non-durable, non-housing) and on the consumption deflator are obtained from the official national accounts for Switzerland, published by the Swiss Federal Statistical Office (annual figures) and the Swiss State Secretariat of Economic Affairs (quarterly, calendar and seasonally adjusted figures).

Regarding financial wealth, the asset side consists of money and deposit holdings, debt securities, shares, units in collective investment schemes, structured products, and claims against pension funds and insurances. On the liability side, financial wealth consists of loans (mortgages, consumer loans and other loans) and other accounts payable. Annual figures from 1999 onwards come from the official Swiss financial accounts. For 1980-1998, the annual figures reflect SNB internal retropolations which are based on the statistic on bank balance sheets, the securities deposits statistic, banknote circulation data, postal account data and insurance statistics. Quarterly financial wealth figures are mostly based on bank statistics if available. For components where quarterly observations are missing, dynamics are approximated by relevant indicators such as the money stock, bond indices and stock market indices.

Housing wealth consists of houses, condominiums and rental apartments valued at market prices and owned by private households. Annual figures are based on internal estimates using data on dwellings from the Federal Register of Buildings and Dwellings (RBD) published by the Swiss Federal Statistical Office and data on hedonic price indices (transaction prices) as follows: For each village in Switzerland, one representative standard property for each of the three property types (single-family homes, condominiums and apartment buildings with rental apartments) is valued by real estate consultancies using hedonic pricing models. These valued standard properties are then multiplied by the number of properties per municipality. For the aggregated property stock over all municipalities, the share of the household sector is taken using a reference value from the

\footnotetext{
${ }^{7}$ Disposable income is published with a lag of two years in Switzerland, so year 2013 cannot be included.
} 
Swiss Housing Census of 2000 (the RBD does not include this information). Before 2000, the RBD data are available only at a 10-year frequency (1980 and 1990). Thus, annual figures on the real estate stock for the 1980-1999 period are obtained by applying the same method as in Schmid (2013), assuming that the change in the annual real estate stock is proportional to data on newly built housing units. Quarterly figures on housing wealth are obtained by interpolation, using quarterly developments of the relevant hedonic price indices. More details on the calculation of financial and housing wealth can be found in Swiss National Bank (2012).

\section{Empirical results}

Most of the results are based on annual instead of quarterly figures. The reason for this is that quarterly measures of both Swiss private consumption and household wealth reflect only interpolated annual figures and thus have limited additional information content. Instead, using interpolated data could lead to erroneous conclusions about the true fundamental dynamics, especially where consumption stickiness is concerned. Using annual figures also has the advantage that quarterly fluctuations in wealth that are only temporary vanish. The only exception to using this strategy of using annual instead of quarterly data is the $\mathrm{KF}$ approach because the true process for consumption is set up in quarterly terms. Given quarterly stickiness parameter $\mathcal{X}_{Q}$, the annual stickiness is then simply given by $\mathcal{X}=\mathcal{X}_{Q}^{4}$.

In what follows, total wealth is defined in net terms, i.e., gross financial wealth plus gross housing wealth minus gross liabilities. When working with separate wealth components (financial wealth and housing wealth), the entire netting is performed on the housing wealth side because $94 \%$ of Swiss household liabilities consist of mortgage loans and are thus directly linked to housing wealth. ${ }^{8}$

In terms of normal priors for the location parameters, we use variances that are large enough so that the priors become loose. For all inverse Wishart and inverse gamma priors, following Bauwens, Lubrano, and Richard (2003), we set the scale parameters and degrees of freedom towards zero so that the priors become non-informative.

To eliminate constants that are of no interest for the analysis, demeaned data are

\footnotetext{
${ }^{8}$ As argued in several studies, the use of more disaggregate wealth measures (e.g., deposits, stock market assets, pension wealth, housing wealth and debt) could potentially be more appropriate because the MPCs of these measures may differ. However, given the limited amount of observations, this is difficult to implement in our case.
} 
Figure 2: Posterior distribution of the consumption stickiness parameter
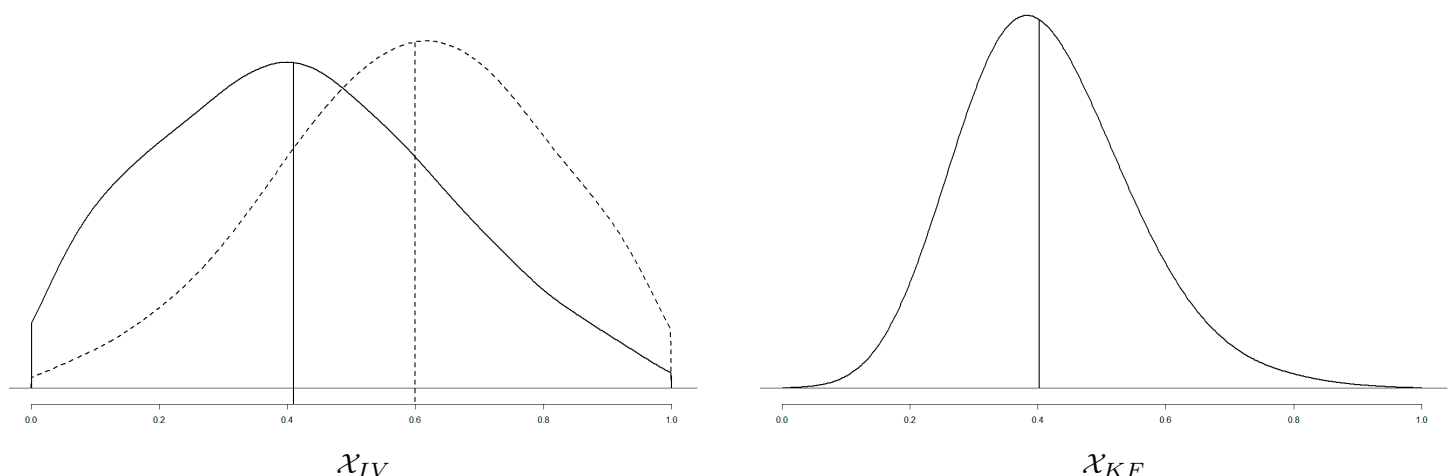

Shown is the estimated posterior density for stickiness parameter $\mathcal{X}$. The left panel shows the posterior obtained from the instrumental variable estimation approach with instruments wealth and disposable income (solid line, median: 0.41) and wealth and consumer sentiment (dashed line, median: 0.60). The right panel shows the posterior obtained from the Kalman filter approach (median: 0.40). Median values are denoted by the vertical lines.

used for all calculations. We use $D=30,000$ draws with 3,000 burn-in draws.

\subsection{Consumption stickiness parameter}

The estimated marginal posterior distribution for $\mathcal{X}$ is shown in Figure 2. Depending on the choice of instrument, the posterior median resulting from the IV approach is either 0.41 (with instruments wealth and disposable income) or 0.60 (with instruments wealth and consumer sentiment). The posterior median resulting from the Kalman filter is 0.40.

Being based on annual data, these values are remarkably high and signal the presence of rather large stickiness in Swiss private consumption expenditures. Viewed in a sticky expectation context, this would mean that only approximately half of the households update their expectations in a given year. In terms of habit formation, this result suggests that a positive change in consumption generates roughly as much utility as the actual level of consumption. In other words, habits are quite important.

Comparing the distributions, it must be noted that the variance of the posterior distribution of the consumption stickiness parameter is rather large in the IV case, compared to the one from the KF approach. This may indicate a weak instrument problem.

From the Kalman Filter, we also obtain smoothed estimated states of true consumption growth. As figure 3 shows, a substantial fraction of the volatility in quarterly consumption growth is due to measurement error and transitory elements, such as weather effects. 
Figure 3: Actual consumption growth compared to estimated path of true consumption growth

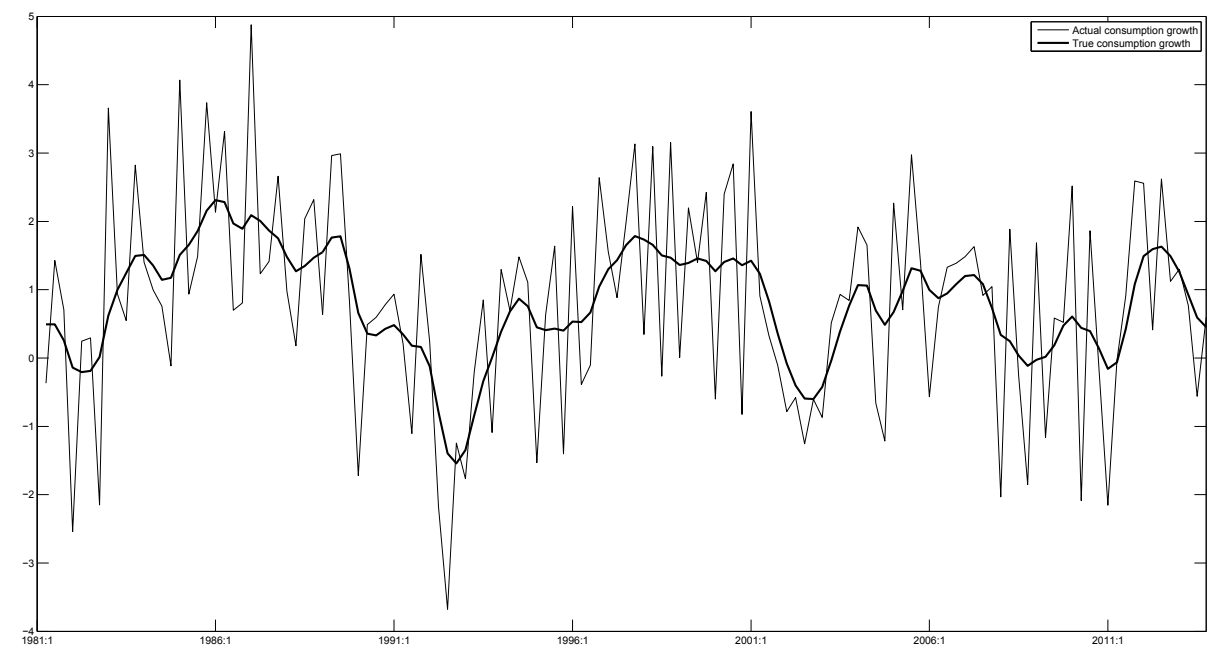

Shown are the Kalman Filter estimates for true consumption growth (median values, bold line) compared to actual quarterly consumption growth in real per capita terms for Switzerland.

\subsection{Short- and long-run wealth effects on consumption}

The marginal posterior distribution for $\alpha$ is shown in Figure 4. Depending on the approach (IV or KF) and the choice of control variable (disposable income or consumer sentiment), the median one-period MPC out of total wealth is between 0.012 and 0.015 . Thus, if total wealth increases by 1 Swiss franc in a given year, consumption rises by 1.2-1.5 Swiss centime at the median the following year. At the 2012 annual levels of consumption (339 billion $\mathrm{CHF}$ ) and total net wealth (3029 billion $\mathrm{CHF}$ ), this means that a $1 \%$ increase in total net wealth yields a $0.11-0.13 \%$ increase in consumption the following year.

From the distributions of the one-period wealth effect, we can also calculate probabilities the for the one-period wealth effect to lying above a certain value: $99.3 \%<p(\alpha>$ $0 \mid y)<99.9 \%, 65 \%<p(\alpha>0.01 \mid y)<88 \%, 26 \%<p(\alpha>0.015 \mid y)<51 \%, 5 \%<p(\alpha>$ $0.02 \mid y)<17 \%$.

The results for the marginal posterior distribution of the long-run wealth effect are shown in Figure 5. Compared to the posterior from the KF approach, the one from the IV approach is much more right-tailed. This is due to the higher variance of $\mathcal{X}_{I V}$, which results in more draws near the extreme values of zero and one, so the multiplier $\frac{1}{\mathcal{X}(1-\mathcal{X})}$ in (22) becomes larger.

The median long-run MPC out of total wealth based on the stickiness parameter 
Figure 4: Posterior distribution of one-period wealth effect
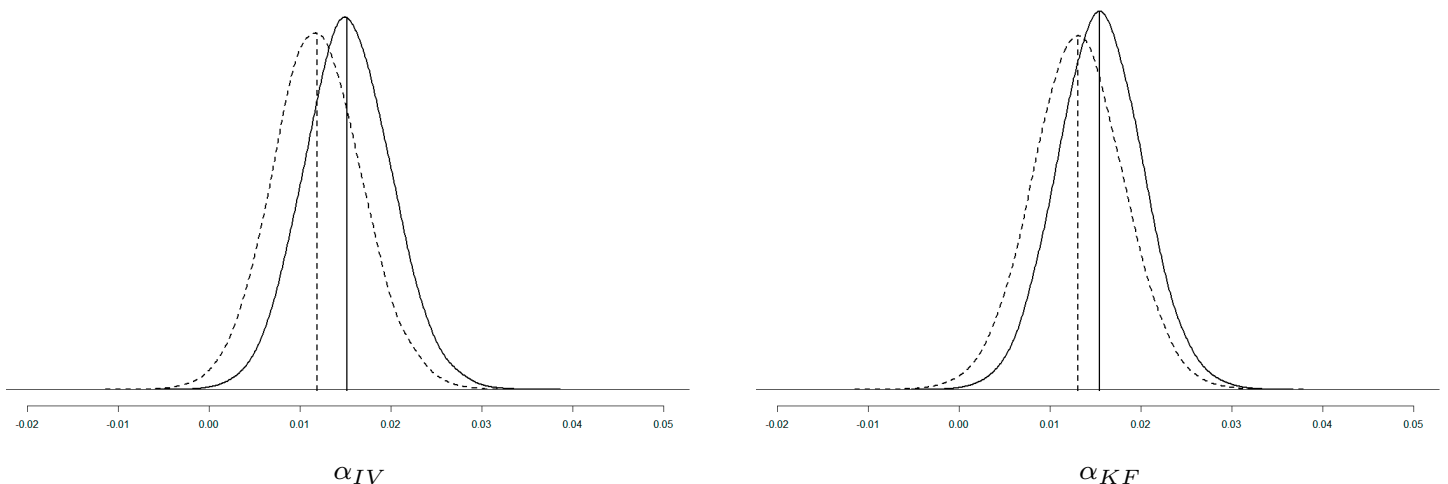

Shown is the estimated posterior distribution of the one-period MPC out of total wealth $(\alpha)$. Left panel: Estimates based on $\mathcal{X}_{I V}$, with control disposable income (solid line, median: 0.015) and with control consumer sentiment (dashed line, median: 0.012). Right panel: Estimates based on $\mathcal{X}_{K F}$ with control disposable income (solid line, median: 0.015) and with control consumer sentiment (dashed line, median: 0.013). Median values are denoted by the vertical lines.

Figure 5: Posterior distribution of long-run wealth effect
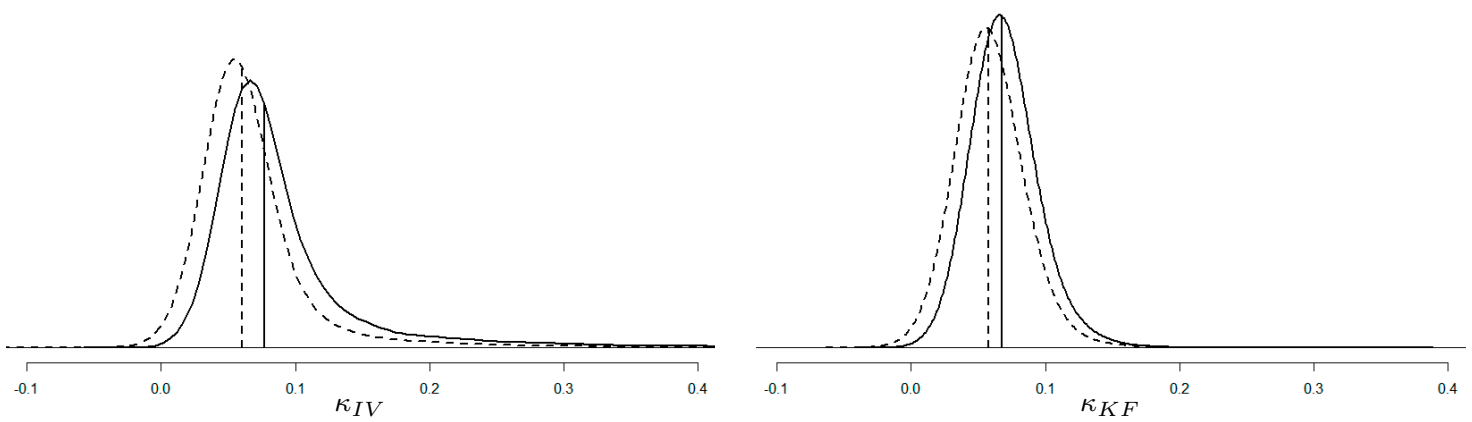

Shown is the estimated posterior distribution of the long-run MPC out of total wealth $(\kappa)$. Left panel: Estimates based on $\mathcal{X}_{I V}$ and $\alpha_{I V}$ with control disposable income (solid line, median: 0.074) and with control consumer sentiment (dashed line, median: 0.059). Right panel: Estimates based on $\mathcal{X}_{K F}$ and $\alpha_{K F}$ with control disposable income (solid line, median: 0.068) and with control consumer sentiment (dashed line, median: 0.057). Median values are denoted by the vertical lines.

from the IV approach is somewhat higher (0.074/0.059, depending on the choice of control) than the MPC based on the KF approach (0.068/0.057, depending on the choice of control). Given these MPC estimates, an increase in total net wealth of one Swiss franc in a given year accumulates - through consumption stickiness - into a long-run consumption increase of 7.4/5.9 centime (IV approach) or 6.8/5.7 centime (KF approach) at the median. At the 2012 annual levels, this means that the infinite horizon effect of a $1 \%$ increase in total net wealth on consumption lies between $0.5 \%$ and $0.66 \%$.

In terms of probabilities, we obtain $99.3 \%<p(\kappa>0 \mid y)<99.9 \%, 63 \%<p(\kappa>$ $0.05 \mid y)<84 \%$ and $5 \%<p(\kappa>0.1 \mid y)<26 \%$, depending on the approach and the choice of control variable. 
Figure 6: Posterior distribution of separate one-period wealth effects
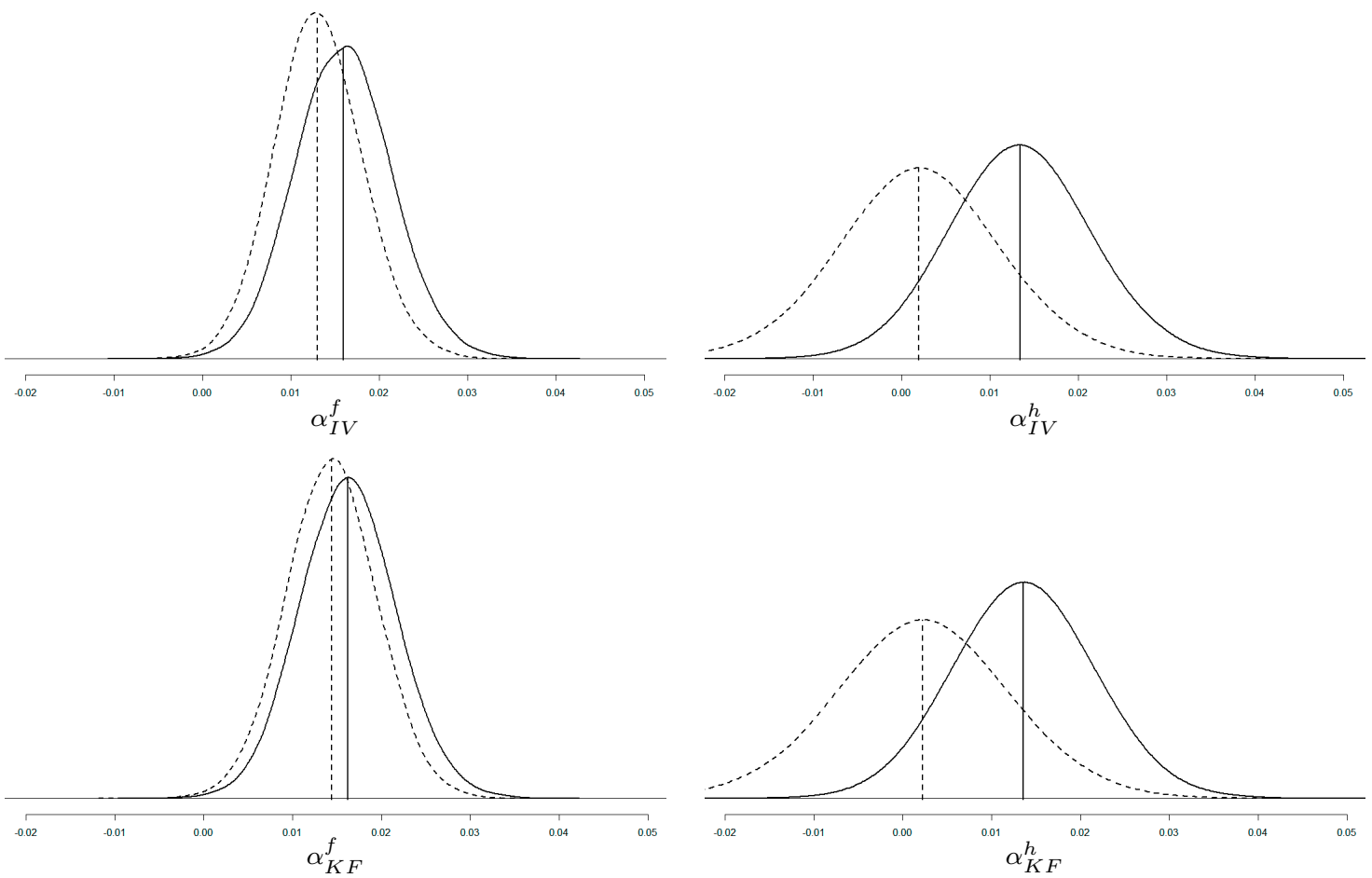

Shown are the estimated posterior distributions of the separate one-period MPC out of financial wealth $\left(\alpha^{f}\right.$, left panel) and housing wealth ( $\alpha^{h}$, right panels) based on $\mathcal{X}_{I V}$ (top panels) and $\mathcal{X}_{K F}$ (bottom panels). Control variables: disposable income (solid line) and consumer sentiment (dashed line). Median values are denoted by the vertical lines.

\subsection{Separating wealth effects}

The results for the short-run separate wealth effects are shown in Figure 6. Depending on the choice of approach and control variable, the median one-period MPC out of financial wealth is estimated to lying between 0.013 and 0.016 .

For the median one-period MPC out of housing wealth, the results are less clear. Whereas using control variable disposable income suggests an MPC of 0.013/0.014 (depending on the approach), using control variable consumer sentiment suggests a median estimate of 0.002 , which is very close to zero. Furthermore, the distribution of the housing wealth effect is much less narrow than for financial wealth. Thus, there is much more uncertainty surrounding the housing wealth effect.

Overall, the results suggest that if financial wealth increases by 1 Swiss franc in a given year, consumption rises by 1.3-1.6 Swiss centime at the median in the following year. For housing wealth, it is 0.2-1.4 Swiss centime at the median. At the 2012 annual levels of consumption, financial wealth (2108 billion CHF) and net housing wealth (921 billion CHF), this means that consumption will increase by $0.08-0.1 \%$ when financial wealth 
Figure 7: Posterior distribution of separate long-run wealth effects
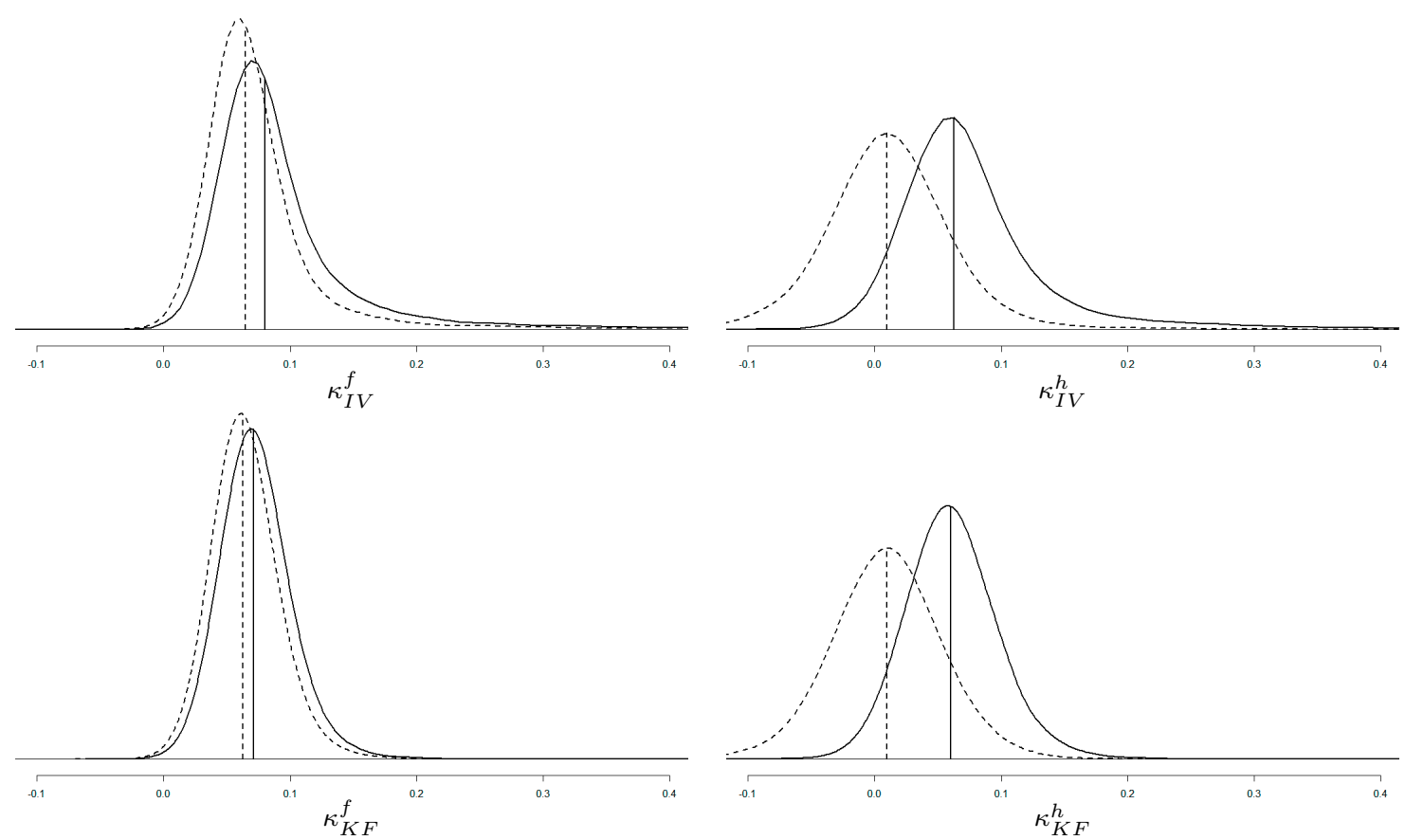

Shown are the estimated posterior distributions of the separate long-run MPC out of financial wealth $\left(\kappa^{f}\right.$, left panel) and housing wealth $\left(\kappa^{h}\right.$, right panels) based on $\mathcal{X}_{I V}$ (top panels) and $\mathcal{X}_{K F}$ (bottom panels). Control variables: disposable income (solid line) and consumer sentiment (dashed line). Median values are denoted by the vertical lines.

increases by $1 \%$ and by $0.01-0.04 \%$ when net housing wealth increases by $1 \%$.

In terms of probabilities, the results are $99.7 \%<p\left(\alpha^{f}>0 \mid y\right)<99.9 \%, 73 \%<$ $p\left(\alpha^{f}>0.01 \mid y\right)<86 \%, 26 \%<p\left(\alpha^{f}>0.015 \mid y\right)<54 \%$ and $4 \%<p\left(\alpha^{f}>0.02 \mid y\right)<17 \%$, while $59 \%<p\left(\alpha^{h}>0 \mid y\right)<95 \%, 18 \%<p\left(\alpha^{h}>0.01 \mid y\right)<69 \%, 7 \%<p\left(\alpha^{h}>0.015 \mid y\right)<$ $43 \%$ and $2 \%<p\left(\alpha^{h}>0.02 \mid y\right)<20 \%$.

For the separate long-run wealth effects, the marginal posteriors are shown in Figure 7. The median long-run MPC out of financial wealth is between 6.3 and 7.8 Swiss centime. The one out of housing wealth is either 6.0/6.7 centime (control variable disposable income) or 1.0 centime (control variable consumer sentiment). Given these MPC estimates, a 1\% increase in financial wealth accumulates - through consumption stickiness - into a longrun effect on consumption of $0.39-0.48 \%$, respectively. A $1 \%$ increase in housing wealth yields an increase in consumption of $0.03-0.18 \%$ in the long-run.

The probability of changes in financial wealth having a positive long-run effect on consumption is between 99.96 and $99.9 \%$; for housing wealth, it is only between $59 \%$ and $96 \%$. The other probabilities are $72 \%<p\left(\kappa^{f}>0.05 \mid y\right)<85 \%$ and $8.4 \%<p\left(\kappa^{f}>\right.$ $0.1 \mid y)<29 \%$, while $16.6 \%<p\left(\kappa^{h}>0.05 \mid y\right)<67 \%$ and $2 \%<p\left(\kappa^{h}>0.1 \mid y\right)<25 \%$. 


\subsection{Comparison with results from other countries and cointegration- based studies}

Carroll, Otsuka, and Slacalek (2011) applied the sticky consumption approach to U.S. data. Their results suggested that the stickiness in quarterly U.S. consumption growth is approximately $0.6-0.7$. The immediate wealth effect in the U.S. was estimated to be approximately 2 cents for a one-dollar increase in wealth, while the long-run total wealth effect accumulates to 5-7 cents. For separate wealth components, the long-run financial wealth effect was found to be approximately 4-6 cents, the long-run housing wealth effect approximately 9-16 cents.

Slacalek (2009) extended the application of the new approach to a broad set of 16 countries. The results are reproduced in Table 1. The left panel shows that the consumption stickiness coefficient $\mathcal{X}$ varies across countries from 0.14 (Germany) to 0.92 (Finland). Large variations are also present in the immediate and long-run MPCs, which are estimated both unrestrictedly with the stickiness parameter relevant for the respective country and with a fixed stickiness parameter of 0.6. The largest wealth effects can be found in Australia, Japan, Denmark, Finland and Spain. In France, Germany, Italy, Austria and Belgium no wealth effects seem to be present.

The right panel shows results for separate financial and housing wealth effects conditional on a stickiness parameter $\mathcal{X}$ of 0.6 . The largest financial wealth effects can be found for Australia, Canada and Japan. The estimates for Germany and Italy are also quite high but are hardly statistically significant. In terms of housing wealth effects, the largest MPC estimates can be found for Australia, Japan, the U.K. and especially Denmark and Finland.

Slacalek (2009) also performed a comparison across country groups. He concluded that total wealth effects seem to be larger in countries with "complete" mortgage markets, in market-based economies, in the U.K., U.S. and in non-euro-area countries. ${ }^{9}$ The same ranking was found for housing wealth effects.

Table 2 summarizes this study's results for Switzerland. Consumption stickiness in Switzerland is among the highest estimates in an international comparison, similar to the degree of stickiness found for Australia, Finland, Ireland, Spain and Sweden. The oneperiod wealth effect, in contrast, is rather small compared to other countries. However,

\footnotetext{
${ }^{9}$ He distinguished between "complete" and "incomplete" mortgage markets using the new mortgage market index of Cardarelli, Igan, and Rebucci (2008). Market-based countries are countries where the stock market plays a more important role thank banks in financial transmission.
} 
Table 1: International results from Salcalek (2009)

\begin{tabular}{|c|c|c|c|c|c|c|}
\hline \multirow[b]{2}{*}{ Country } & \multirow[b]{2}{*}{ Time Range } & \multicolumn{3}{|c|}{$\chi$ Unrestricted } & \multicolumn{2}{|c|}{$\chi=0.60$} \\
\hline & & $\chi$ & $\mathrm{MPC}_{w}^{\mathrm{im}}$ & $\mathrm{MPC}_{w}^{\mathrm{ev}}$ & $\mathrm{MPC}_{w}^{\mathrm{im}}$ & $\mathrm{MPC}_{w}^{\mathrm{ev}}$ \\
\hline Australia & 70Q1-99Q4 & 0.84 & $1.64^{* * *}$ & $10.05^{* * *}$ & $2.86^{* * *}$ & $7.14^{* * *}$ \\
\hline Canada & 70Q1-03Q3 & 0.74 & $1.06^{* *}$ & $4.06^{* *}$ & $1.70^{* * * *}$ & $4.25^{* * *}$ \\
\hline France & $70 \mathrm{Q} 2-03 \mathrm{Q} 2$ & 0.22 & 3.57 & 4.60 & 1.07 & 2.69 \\
\hline Germany & $70 \mathrm{Q} 1-02 \mathrm{Q} 4$ & 0.14 & 6.61 & 7.70 & $1.33^{*}$ & $3.32^{*}$ \\
\hline Italy & 71Q4-99Q4 & 0.74 & -0.25 & -0.95 & -0.33 & -0.83 \\
\hline Japan & 70Q1-01Q1 & 0.20 & $10.57^{* *}$ & $13.15^{* *}$ & $2.97^{* * *}$ & $7.44^{* * *}$ \\
\hline United Kingdom & 70Q1-03Q4 & 0.62 & $2.00^{* * *}$ & $5.31^{* * *}$ & $2.12^{\text {*** }}$ & $5.31^{* * *}$ \\
\hline United States & 65Q1-03Q4 & 0.74 & $1.53^{* * *}$ & $5.95^{* * *}$ & $2.16^{* * *}$ & $5.41^{* * *}$ \\
\hline Austria & $78 \mathrm{Q} 2-02 \mathrm{Q} 4$ & 0.40 & 0.13 & 0.21 & 0.06 & 0.14 \\
\hline Belgium & $80 \mathrm{Q} 2-02 \mathrm{Q} 4$ & 0.66 & -0.05 & -0.14 & -0.01 & -0.02 \\
\hline Denmark & 77Q1-01Q4 & 0.55 & $4.33^{* * *}$ & $9.68^{* * *}$ & $3.72^{* * *}$ & $9.29^{* * *}$ \\
\hline Finland & 79Q1-03Q1 & 0.92 & $1.95^{* * *}$ & $24.08^{* * *}$ & $4.03^{* * *}$ & $10.08^{* * *}$ \\
\hline Ireland & $75 \mathrm{Q} 4-96 \mathrm{Q} 4$ & 0.86 & 0.80 & 5.57 & $1.84^{*}$ & $4.59^{*}$ \\
\hline Netherlands & 75Q1-02Q4 & 0.51 & $1.27^{* *}$ & $2.60^{* *}$ & $1.14^{* *}$ & $2.84^{* *}$ \\
\hline Spain & $87 \mathrm{Q} 1-02 \mathrm{Q} 4$ & 0.84 & $1.29^{* * *}$ & $8.32^{* * *}$ & $2.38^{* * *}$ & $5.96^{* * *}$ \\
\hline Sweden & $77 \mathrm{Q} 1-02 \mathrm{Q} 4$ & 0.88 & $0.83^{* *}$ & $6.91^{* *}$ & $1.84^{* *}$ & $4.61^{* *}$ \\
\hline ean & - & 0.62 & 2.33 & 6.69 & 1.81 & 4.51 \\
\hline
\end{tabular}

\begin{tabular}{|c|c|c|c|}
\hline \multirow[b]{2}{*}{ Country } & \multirow[b]{2}{*}{ Time Range } & \multicolumn{2}{|c|}{ Wealth } \\
\hline & & Financial & Housing \\
\hline Australia & 70Q1-99Q4 & $7.26^{* * *}$ & $7.10^{* * *}$ \\
\hline Canada & 70Q1-03Q3 & $8.05^{* *}$ & 1.28 \\
\hline France ${ }^{\dagger}$ & $70 \mathrm{Q} 2-03 \mathrm{Q} 2$ & $2.89^{*}$ & 2.30 \\
\hline Germany $^{\dagger}$ & $70 \mathrm{Q} 1-02 \mathrm{Q} 4$ & 14.24 & 2.86 \\
\hline Italy $y^{t}$ & 71Q4-99Q4 & $10.30^{*}$ & $-1.07^{*}$ \\
\hline$J^{\prime} a n^{\ddagger}$ & 70Q1-01Q1 & $9.48^{* *}$ & $6.30^{* * *}$ \\
\hline United Kingdom & 70Q1-03Q4 & $3.71^{*}$ & $6.95^{* * *}$ \\
\hline United States & 65Q1-03Q4 & $5.33^{* * *}$ & 7.04 \\
\hline Austria $^{\dagger}$ & $78 \mathrm{Q} 2-02 \mathrm{Q} 4$ & 0.40 & -2.17 \\
\hline Belgium $^{\dagger}$ & $80 \mathrm{Q} 2-02 \mathrm{Q} 4$ & 0.63 & -6.74 \\
\hline Denmark & 77Q1-01Q4 & 5.95 & $17.33^{* *}$ \\
\hline Finland & 79Q1-03Q1 & -3.58 & $18.15^{* * *}$ \\
\hline Ireland & 75Q4-96Q4 & 2.09 & $9.15^{*}$ \\
\hline Netherlands & $75 \mathrm{Q} 1-02 \mathrm{Q} 4$ & $2.68^{*}$ & 3.17 \\
\hline Spain & 87Q1-02Q4 & $5.33^{* *}$ & $6.24^{* * *}$ \\
\hline Sweden & 77Q1-02Q4 & $5.74^{* *}$ & 2.56 \\
\hline Mean & & 5.03 & 5.03 \\
\hline
\end{tabular}

Table 2: Summary of results for Switzerland

\begin{tabular}{l|c|ccc|cc}
\hline & \multirow{2}{*}{} & \multicolumn{3}{|c|}{ Aggregate wealth } & \multicolumn{2}{c}{ Separate wealth } \\
\cline { 3 - 7 } & Time Range & $\mathcal{X}$ & $\mathrm{MPC}_{w}^{i m}$ & $\mathrm{MPC}_{w}^{e v}$ & $\begin{array}{c}\text { Financial } \\
\mathrm{MPC}_{w}^{e v}\end{array}$ & $\begin{array}{c}\text { Housing } \\
\mathrm{MPC}_{w}^{e v}\end{array}$ \\
\hline Switzerland (IV) & $1980-2012$ & $0.80 / 0.88$ & $1.3 / 0.6$ & $7.4 / 5.9$ & $7.8 / 6.5$ & $6.7 / 1.0$ \\
Switzerland (KF) & $1980-2012$ & 0.80 & $1.3 / 1.1$ & $6.8 / 5.7$ & $7.1 / 6.3$ & $6.0 / 1.0$ \\
\hline Controls: disposable income/consumer sentiment \\
Note: The estimates for $\mathcal{X}$ and $\kappa^{i m}$ are transformed to quarterly frequency. \\
\hline
\end{tabular}

given the high degree of stickiness of Swiss private consumption, the wealth effect accumulates to a larger extent over time so that the long-run effect eventually lies somewhere in the middle of the international results. The same applies to the separate financial and housing wealth effects.

When comparing the results to the ones obtained in the cointegration-based study for Switzerland of Galli (2016), wealth effects are found to be substantially higher than indicated by the cointegration-based results, which suggested - driven by the sample since 2001 - that wealth effects are hardly present. Thus, changes in wealth do have a long-run effect on consumption in Switzerland, but a stable level-relationship between consumption and wealth no longer seems to exist. This also implies the absence of error-correction mechanisms. 


\section{Conclusions}

For Switzerland, the question of how changes in wealth affect household expenditures is particularly interesting today. Large increases in stock prices and real estate prices have led to a strong increase in Swiss household wealth over the past few years. From 2004 to 2014, per capita wealth rose by almost $40 \%$. To assess the extent to which such increases in household wealth affect household expenditures, most empirical studies have used cointegration-based approaches. These approaches rely on the existence of a stable long-run relationship among consumption, wealth and income. However, as documented in Galli (2016), no such stable relationship among consumption, wealth and income has seemed to exist in Switzerland since 2001. This makes cointegration-based results for wealth effects - which suggest that no wealth effects are present in Switzerland - much less reliable.

Motivated by this issue, this study applied the relatively new approach of Carroll, Otsuka, and Slacalek (2011) to estimate long-run wealth effects in Switzerland. The approach relies not on cointegration but rather on sticky consumption growth, motivated by consumption habits or sticky expectations. In both cases, long-run wealth effects are then the result of short-run reactions of households to changes in wealth that become long-lasting.

This paper contains four main results: First, there seems to be a remarkably high degree of consumption stickiness in Switzerland. Viewed in a sticky expectation context, only approximately half of households update their expectations and optimize their consumption behavior in a given year. Therefore, consumption growth is quite persistent even on an annual basis. In terms of habit formation, the results suggest that a positive change in consumption generates roughly as much utility as the actual level of consumption. In other words, habits are quite important.

Second, wealth effects in Switzerland are substantially larger (between 5.7 and 7.4 Swiss centime at the median) than indicated by the cointegration-based results from Galli (2016), which suggested - driven by the sample since 2001 - that wealth effects are hardly present in Switzerland. Thus, changes in wealth do have a long-run effect on consumption, but a stable level-relationship between consumption and wealth no longer seems to exist. This also implies the absence of error-correction mechanisms.

Third, the results for separate financial and housing wealth effects suggest that the 
median one-period MPC somewhat higher out of financial wealth (0.017) than out of total wealth, and the one out of housing wealth is somewhat smaller (0.011). In addition, there is a much higher degree of uncertainty surrounding the latter. This supports the point mentioned by Galli (2016) that changes in housing wealth do not necessarily need to create aggregate gains and thus affect aggregate consumption.

Fourth, a comparison with estimates for other countries reveals that the degree of stickiness in Swiss private consumption is among the highest. Furthermore, in terms of wealth effects, the short-run wealth effect is rather small compared to other countries. However, given the high degree of stickiness of Swiss private consumption, changes in wealth in a given period have an effect on consumption not only in the next period but also, to large extent, in upcoming periods. Thus, the accumulated long-run effect lies somewhere in the middle of the international results. The same applies to the separate financial and housing wealth effects. 


\section{Bibliography}

Aron, J., J. V. Duca, J. Muellbauer, K. Murata, and A. Murphy (2011): "Credit, Housing Collateral, and Consumption: Evidence from Japan, the U.K., and the U.S.," Review of Income and Wealth, 58.

Aron, J., J. Muellbauer, and A. Murphy (2008): "Housing wealth, credit conditions and UK consumption," 2008 European Meeting of the Econometric Society, Milan, Italy, August 27-31, 2008.

Bauwens, L., M. Lubrano, And J.-F. Richard (2003): Bayesian inference in dynamics econometric models. Oxford Unversity Press.

Benjamin, J. D., P. Chinloy, and G. D. Jud (2004): "Real estate versus financial wealth in consumption," Journal of Real Estate Finance and Economics, 29.

Cardarelli, R., D. Igan, and A. Rebucci (2008): "The changing housing cycle and the implications for monetary policy," World Economic Outlook, April 2008, 103-133.

Carroll, C. D., M. Otsuka, and J. Slacalek (2011): "How large are housing and financial wealth effects? A new approach," Journal of Money, Credit and Banking, 43.

Carroll, C. D., and J. Slacalek (2006): "Sticky expectations and consumption dynamics," mimeo, Johns Hopkins University.

Carroll, C. D., J. Slacalek, and M. Sommer (2011): "International evidence on sticky consumption growth," The Review of Economics and Statistics, 93.

Carter, C. K., and P. Kohn (1994): "On Gibbs sampling for state space models," Biometrica, 81, 541-553.

Cogley, T., and R. Startz (2012): "Bayesian IV: the normal case with multiple endogenous variables," University of California at Santa Barbara, Economics Working Paper Series.

Cooper, D., And K. Dynan (2014): "Wealth effects and macroeconomic dynamics," Journal of Economic Surveys.

Dynan, K. E. (2000): "Habit formation in consumer preferences: Evidence from panel data," American Economic Review, 90, 391-406. 
Fisher, L. A., AND G. M. Voss (2004): "Consumption, wealth and expected stock returns in Australia," The Economic Record, 80, 359-372.

GALLI, A. (2016): "How reliable are cointegration-based estimates for wealth effects on consumption? Evidence from Switzerland," SNB Working Paper Series, 2016-03.

Hamburg, B., M. Hoffmann, and J. Keller (2008): "Consumption, wealth and business cycles in Germany," Empirical Economics, 34, 481-476.

Kim, C.-J., And C. R. Nelson (1999): State-space models with regime switching. The MIT Press, Cambridge, Massachusetts.

Kleibergen, F., and E. Zivot (2003): "Bayesian and classical approaches to instrumental variable regression," Journal of Econometrics, 114, 29-72.

Koop, G. (2003): Bayesian Econometrics. Wiley.

Lancaster, T. (2004): An introduction to modern bayesian econometrics. Blackwell.

Lettau, M., And S. Ludvigson (2001): "Consumption, aggregate wealth, and expected stock returns," The Journal of Finance, 56.

(2004): "Understanding trend and cycle in asset values: Reevaluating the wealth effect on consumption," American Economic Review, 94.

Muellbauer, J. (1988): "Habits, rationality and myopia in the life cycle consumption function," Annales d'economie et de statistique, 9.

Muellbauer, J. N. (2007): Housing, credit and consumer expenditure. Jackson Hole Symposium, Federal Reserve Bank of Kansas City.

Rossi, P., M. Allenby, and R. McCulloch (2005): Bayesian statistics and marketing. John Wiley \& Sons.

Schmid, F. (2013): "Wealth effects on consumption in Switzerland," Swiss Journal of Economics and Statistics, 149, 87-110.

SlacAleK, J. (2009): "What drives personal consumption? The role of housing and financial wealth," The B.E. Journal of Macroeconomics, 9.

Sommer, M. (2007): "Habit formation and aggregate consumption dynamics," The B.E. Journal of Macroeconomics, 7. 
SousA, R. M. (2010): "Wealth effects on consumption: evidence from the Euro area," Bank and Bank Systems, 7.

Swiss National Bank (2012): $\quad$ "Household Wealth 2012,"
http://www.snb.ch/en/iabout/stat/statpub/vph/stats/wph.




\section{A Sampling techniques}

\section{A.1 Consumption stickiness parameter}

\section{A.1.1 Instrumental variable approach}

Substituting the first-stage equation

$$
\partial C_{-1}^{o b s}=Z \gamma+v
$$

into the structural equation

$$
\partial C^{o b s}=\mathcal{X} \partial C_{-1}^{o b s}+\varepsilon
$$

yields the second-stage equation (also known as restricted reduced form):

$$
\partial C^{o b s}=Z \gamma \mathcal{X}+\varepsilon+v \mathcal{X}
$$

Putting the first-stage and second-stage equations in a seemingly-unrelated regression form, we obtain

$$
\left[\begin{array}{c}
\partial C^{o b s} \\
\partial C_{-1}^{o b s}
\end{array}\right]=\left[\begin{array}{cc}
Z & 0 \\
0 & Z
\end{array}\right]\left[\begin{array}{c}
\gamma \mathcal{X} \\
\gamma
\end{array}\right]+\underbrace{\left[\begin{array}{c}
\varepsilon+\mathcal{X} v \\
v
\end{array}\right]}_{\equiv w},
$$

with $w_{t} \sim \operatorname{iidN}\left(0, \Sigma_{w}\right)$.

I use the Bayesian instrumental variable Gibbs sampler outlined in Cogley and Startz (2012). The Gibbs sampler steps are the following ${ }^{10}$ :

1. Set starting values $\mathcal{X}^{0}=\underline{\mathcal{X}}, \gamma^{0}=\underline{\gamma}$

2. Repeat the following step for $d=1 \ldots \mathrm{D}$, where $\mathrm{D}$ is the number of draws

2.1 Take a random draw $\Sigma_{w}^{(d)}$ from $p\left(\Sigma_{w} \mid \mathcal{X}^{(d-1)}, \gamma^{(d-1)}\right)$

2.2 Take a random draw $\mathcal{X}^{(d)}$ from $p\left(\mathcal{X} \mid \gamma^{(d-1)}, \Sigma_{w}^{(d)}\right)$, use it if it lies within $(-1,1)$, otherwise draw again

2.3 Take a random draw $\gamma^{(d)}$ from $p\left(\gamma \mid \mathcal{X}^{(d)}, \Sigma_{w}^{(d)}\right)$

3. Get rid of the first B draws of $\mathcal{X}, \gamma$ and $\Sigma_{w}$ (burn-in draws)

4. Approximate the distribution, the expected value and the variance from the remaining D-B draws. The expected value for parameter $\theta$ is best approximated by

\footnotetext{
${ }^{10}$ All posterior distributions are also conditional on the date. For the sake of simplicity, we omitted this in the formulas throughout this appendix.
} 


$$
\hat{\theta}=\frac{1}{D-B} \sum_{d=B+1}^{D} \theta^{(d)}
$$

To sample from $p\left(\Sigma_{w} \mid \gamma, \mathcal{X}\right)$, we make use of the fact that conditional on $\gamma$ and $\mathcal{X}, w$ is observable. Combined with the inverse Wishart prior on $\Sigma_{w}$, the conditional posterior for $\Sigma_{w}$ is inverse Wishart and given by

$$
\Sigma_{w} \mid \gamma, \mathcal{X} \sim I W\left(\bar{S}=\underline{S}+w w^{\prime}, \overline{D F}=\underline{D F}+N\right)
$$

To sample from $p\left(\mathcal{X} \mid \gamma, \Sigma_{w}\right)$, we rewrite the equation system as

$$
\left[\begin{array}{c}
\partial C \\
\partial C_{-1}-Z \gamma
\end{array}\right]=\left[\begin{array}{c}
Z \gamma \\
0
\end{array}\right] \mathcal{X}+\left[\begin{array}{c}
\varepsilon+\mathcal{X} v \\
v
\end{array}\right]
$$

Since $\gamma$ is known, the residual of the second row of the equation system is conditionally observable. Furthermore, since the elements of $w$ are jointly normal, we have

$$
\varepsilon+\mathcal{X} v \mid v \sim N\left(v \frac{1}{\sigma_{v}^{2}} \operatorname{Cov}[\varepsilon+\mathcal{X} v, v], \sigma_{\varepsilon+v \mathcal{X}}^{2}-\frac{1}{\sigma_{v}^{2}} \operatorname{Cov}[v, \varepsilon+v \mathcal{X}]^{2}\right) .
$$

By subtracting $E[\varepsilon+\mathcal{X} v \mid v]$ from both sides of the equation and defining the transformed residual by $\eta \equiv \varepsilon+\mathcal{X} v-E[\varepsilon+\mathcal{X} v \mid v]$, we can rewrite the equation system further as

$$
\left[\begin{array}{c}
\partial C-E[\varepsilon+\mathcal{X} v \mid v] \\
\partial C_{-1}-\partial \hat{C}_{-1}
\end{array}\right]=\left[\begin{array}{c}
\partial \hat{C}_{-1} \\
0
\end{array}\right] \mathcal{X}+\left[\begin{array}{l}
\eta \\
v
\end{array}\right] \text { where } \partial \hat{C}_{-1}=Z \gamma
$$

Since $\eta$ has conditional mean zero and is conditionally independent of $v$, only the first row is relevant for estimating $\mathcal{X}$. Combined with the normal prior on $\mathcal{X}$, the conditional posterior for $\mathcal{X}$ is normal and given by

$$
\mathcal{X} \mid \gamma, \Sigma_{w} \sim N\left(\overline{\mathcal{X}}=\bar{V}_{\mathcal{X}}\left(\underline{V}_{\mathcal{X}}{ }^{-1} \underline{\mathcal{X}}+\partial \hat{C}_{-1}^{\prime}(\partial C-E[\varepsilon+\mathcal{X} v \mid v]) \sigma_{\eta}^{-2}\right), \bar{V}_{\mathcal{X}}=\sigma_{\eta}^{2}\left(\sigma_{\eta}^{2} \underline{V}_{\mathcal{X}}^{-1}+\partial \hat{C}_{-1}{ }^{\prime} \partial \hat{C}_{-1}\right)^{-1}\right)
$$

Note that $\sigma_{\eta}^{2}=\operatorname{Var}(\varepsilon+\mathcal{X} v \mid v)$.

To sample from $p\left(\gamma \mid \mathcal{X}, \Sigma_{w}\right)$, we rewrite the equation system as

$$
\underbrace{\left[\begin{array}{c}
\partial C \\
\partial C_{-1}
\end{array}\right]}_{\tilde{y}}=\underbrace{\left[\begin{array}{c}
\mathcal{X} Z \\
Z
\end{array}\right]}_{\tilde{X}} \gamma+\underbrace{\left[\begin{array}{c}
\varepsilon+\mathcal{X} v \\
v
\end{array}\right]}_{\equiv w} .
$$


When $\mathcal{X}$ is known, this is a seemingly unrelated regression which is linear in the unknown parameter $\gamma$. Combined with the normal prior on $\gamma$, the conditional posterior for $\gamma$ is normal and given by

$$
\gamma \mid \mathcal{X}, \Sigma_{w} \sim N\left(\bar{\gamma}=\bar{V}_{\gamma}\left(\underline{V}_{\gamma}^{-1} \underline{\underline{\gamma}}+\sum_{i=1}^{k+1} \tilde{X}_{i}^{\prime} \Sigma_{w}^{-1} \tilde{y}_{i}\right), \underline{V}_{\gamma}^{-1}+\sum_{i=1}^{k+1} \tilde{X}_{i}^{\prime} \Sigma_{w}^{-1} \tilde{X}_{i}\right)
$$

Using these conditional posterior distributions in the Gibbs sampling procedure results in approximate marginal distributions of the parameters $\mathcal{X}, \gamma$ and $\Sigma_{w}$.

\section{A.1.2 Kalman Filter approach}

The state space form system, where consumption decisions are made on a monthly basis and consumption is observed at a quarterly frequency, is represented by measurement equation

$$
\Delta \log C_{t}^{o b s}=\left[\begin{array}{lllll}
1 & 0 & 1 & 0 & 0
\end{array}\right]\left[\begin{array}{c}
\Delta \log C_{t} \\
-u_{t} \\
\Delta u_{t} \\
\varepsilon_{t} \\
\varepsilon_{t-1}
\end{array}\right]
$$

and transition equation

$$
\underbrace{\left[\begin{array}{c}
\Delta \log C_{t} \\
-u_{t} \\
\Delta u_{t} \\
\varepsilon_{t} \\
\varepsilon_{t-1}
\end{array}\right]}_{\beta_{t}}=\left[\begin{array}{ccccc}
\mathcal{X} & 0 & 0 & \lambda_{1}(\mathcal{X}) & \lambda_{2}(\mathcal{X}) \\
0 & 0 & 0 & 0 & 0 \\
0 & 1 & 0 & 0 & 0 \\
0 & 0 & 0 & 0 & 0 \\
0 & 0 & 0 & 1 & 0
\end{array}\right] \underbrace{\left[\begin{array}{c}
\Delta \log C_{t-1} \\
-u_{t-1} \\
\Delta u_{t-1} \\
\varepsilon_{t-1} \\
\varepsilon_{t-2}
\end{array}\right]}_{\beta_{t-1}}+\left[\begin{array}{c}
\varepsilon_{t} \\
-u_{t} \\
u_{t} \\
\varepsilon_{t} \\
0
\end{array}\right]
$$

with

$$
Q=\left[\begin{array}{ccccc}
\sigma_{\varepsilon}^{2} & 0 & 0 & \sigma_{\varepsilon}^{2} & 0 \\
0 & \sigma_{u}^{2} & -\sigma_{u}^{2} & 0 & 0 \\
0 & -\sigma_{u}^{2} & \sigma_{u}^{2} & 0 & 0 \\
\sigma_{\varepsilon}^{2} & 0 & 0 & \sigma_{\varepsilon}^{2} & 0 \\
0 & 0 & 0 & 0 & 0
\end{array}\right]
$$


If consumption decisions are made at the same frequency as consumption is observed, the estimation setup still applies after setting $\lambda_{1}=\lambda_{2}=0$, which we do for the reasons mentioned at the beginning of section 3 .

I use the Gibbs sampler applied for a state space model following Kim and Nelson (1999). The Gibbs sampler steps are the following:

1. Set starting values $\mathcal{X}^{0}, \gamma^{0}, \sigma_{\varepsilon}^{2^{0}}, \sigma_{u}^{2^{0}}$

2. Repeat the following step for $d=1 \ldots \mathrm{D}$, where $\mathrm{D}$ is the number of draws

2.0 Take a random draw $\beta^{(d)}$ from $p\left(\beta_{t} \mid \mathcal{X}, \sigma_{\varepsilon}^{2}, \sigma_{u}^{2}\right)$

2.1 Take a random draw $\mathcal{X}^{(d)}$ from $p\left(\mathcal{X} \mid \sigma_{\varepsilon}^{2}, \Delta C_{t}\right)$, use it if it lies within $(-1,1)$, otherwise draw again

2.2 Take a random draw $\sigma_{\varepsilon}^{2^{(d)}}$ from $p\left(\sigma_{\varepsilon}^{2} \mid \mathcal{X}, \Delta C_{t}\right)$

2.3 Take a random draw $\sigma_{u}^{2(d)}$ from $p\left(\sigma_{u}^{2} \mid \Delta C_{t}\right)$

3. Get rid of the first $\mathrm{B}$ draws of $\beta, \mathcal{X}, \sigma_{\varepsilon}^{2}$ and $\sigma_{u}^{2}$ (burn-in draws)

4. Approximate the distribution, the expected value and the variance from the remaining D-B draws. The expected value for parameter $\theta$ is best approximated by $\hat{\theta}=\frac{1}{D-B} \sum_{d=B+1}^{D} \theta^{(d)}$

To sample from $p\left(\beta_{t} \mid \mathcal{X}, \sigma_{\varepsilon}^{2}, \sigma_{u}^{2}\right)$ we run the Kalman filter conditional on all the parameters of the model and the observed data to obtain filtered estimates for the state vector, denoted by $\beta_{t \mid t}$ and the related covariance matrices $P_{t \mid t}$ for $t=1 . . T$. Based on these, we generate $\beta_{T}$ by drawing from

$$
\beta_{T} \mid \mathcal{X}, \sigma_{\varepsilon}^{2}, \sigma_{u}^{2} \sim N\left[\beta_{T \mid T}, P_{T \mid T}\right]
$$

and for $t<T$ by applying the simulation smoother from Carter and Kohn (1994), i.e., drawing $\beta_{t \mid T}$ from $N\left[\beta_{t \mid t}+P_{t \mid t} F^{\prime}\left(F P_{t \mid t} F^{\prime}+Q\right)^{-1}\left(\beta_{t+1}-F \beta_{t \mid t}\right), P_{t \mid t}-P_{t \mid t} F^{\prime}\left(F P_{t \mid t} F^{\prime}+\right.\right.$ $\left.Q)^{-1} F P_{t \mid t}\right]$. However, since $Q$ is singular, we have to restrict $\mathrm{Q}$ to its non-singular part $\mathrm{Q}^{*}$, which is given by the first $4 \mathrm{x} 4$ block of it. Therefore we also have to restrict $F$ to $F^{*}$ and $\beta^{*}$, which are the first 4 rows of $F$ and $\beta$, respectively. Therefore, we draw from $\beta_{t} \mid \mathcal{X}, \sigma_{\varepsilon}^{2}, \sigma_{u}^{2} \sim N\left[\beta_{t \mid t}+P_{t \mid t} F^{* \prime}\left(F^{*} P_{t \mid t} F^{* \prime}+Q^{*}\right)^{-1}\left(\beta_{t+1}^{*}-F^{*} \beta_{t \mid t}\right), P_{t \mid t}-P_{t \mid t} F^{* \prime}\left(F^{*} P_{t \mid t} F^{* \prime}+Q^{*}\right)^{-1} F^{*} P_{t \mid t}\right]$.

To sample from $p\left(\mathcal{X} \mid \sigma_{\varepsilon}^{2}, \Delta C_{t}\right)$ and $p\left(\sigma_{\varepsilon}^{2} \mid \mathcal{X}, \Delta C_{t}\right)$, we make use of the fact that conditional on the state vector, the equation (11) is an independent $\operatorname{ARMA}(1,2)$ model with 
autocorrelated disturbances. This model can be written in state space form, with the measurement equation

$$
\Delta \log C_{t}=\left[\begin{array}{lll}
1 & \lambda_{1}(\mathcal{X}) & \lambda_{2}(\mathcal{X})
\end{array}\right]\left[\begin{array}{c}
\xi_{t} \\
\xi_{t-1} \\
\xi_{t-2}
\end{array}\right]
$$

where $\xi_{t}$ is a non-interpretable state variable. The transition equation is given by

$$
\left[\begin{array}{c}
\xi_{t} \\
\xi_{t-1} \\
\xi_{t-2}
\end{array}\right]=\left[\begin{array}{lll}
\mathcal{X} & 0 & 0 \\
1 & 0 & 0 \\
0 & 1 & 0
\end{array}\right]\left[\begin{array}{c}
\xi_{t-1} \\
\xi_{t-2} \\
\xi_{t-3}
\end{array}\right]+\left[\begin{array}{c}
\varepsilon_{t} \\
0 \\
0
\end{array}\right]
$$

Conditional on $\sigma_{\varepsilon}^{2}$ and $\Delta C_{t}$, we run the Kalman filter to obtain filtered estimates for $\xi$, denoted by $\xi_{t \mid t}$, and the related covariance matrix $P_{t \mid t}^{\xi}$. Based on these, we generate $\xi_{t}$ for $t=T$ by drawing from

$$
N\left(\xi_{T \mid T}, P_{T \mid T}^{\xi}\right)
$$

and for $t<T$ by applying the Carter-Kohn simulation smoother and drawing from

$$
N\left(\xi_{t \mid t}+P_{t \mid t}^{\xi} F^{* \prime}\left(F^{*} P_{t \mid t}^{\xi} F^{* \prime}+Q\right)^{-1}\left(\xi_{t+1}^{*}-F^{*} \xi_{t \mid t}\right), P_{t \mid t}^{\xi}-P_{t \mid t}^{\xi} F^{* \prime}\left(F^{*} P_{t \mid t}^{\xi *} F^{\prime}+Q\right)^{-1} F^{*} P_{t \mid t}^{\xi}\right)
$$

Conditional on $\sigma_{\varepsilon}^{2}$ and $\xi$, we can then draw $\mathcal{X}$ from the following normal posterior distribution:

$$
\mathcal{X} \mid \sigma_{\varepsilon}^{2}, \Delta C_{t} \sim N\left[\overline{\mathcal{X}}=\bar{V} \mathcal{X}\left(\underline{V \mathcal{X}}^{-1} \underline{\mathcal{X}}+\sigma_{\varepsilon}^{-2} \xi_{-1}^{\prime} \xi\right), \bar{V} \mathcal{X}=\left(\underline{V \mathcal{X}}^{-1}+\sigma_{\varepsilon}^{-2} \xi_{-1}^{\prime} \xi_{-1}\right)^{-1}\right]
$$

Finally, given our draw of $\xi$ and $\mathcal{X}$, we can draw $\sigma_{\varepsilon}^{2}$ from the following inverse gamma posterior distribution:

$$
\sigma_{\varepsilon}^{2} \mid \mathcal{X}, \Delta C_{t} \sim I G\left[\frac{d_{1}+T}{2}, \frac{d_{2}+\left(\xi-\xi_{-1} \mathcal{X}\right)^{\prime}\left(\xi-\xi_{-1} \mathcal{X}\right)}{2}\right]
$$

To draw from $p\left(\sigma_{u}^{2} \mid \Delta C_{t}\right)$, we make use of the fact that conditional on the states, the equation (12) is independent. Therefore, we can draw $\sigma_{u}^{2}$ from the following inverse 
gamma posterior distribution:

$$
\sigma_{u}^{2} \mid \Delta C_{t} \sim \frac{1}{2} I G\left[\frac{d_{3}+T}{2}, \frac{d_{4}+\left(\Delta C^{o b s}-\Delta C\right)^{\prime}\left(\Delta C^{o b s}-\Delta C\right)}{2}\right]
$$

Using these conditional posterior distributions in the Gibbs sampling procedure results in approximate marginal distributions of the states $\beta$ and the parameters $\mathcal{X}, \sigma_{\varepsilon}^{2}$ and $\sigma_{u}^{2}$.

\section{A.2 Short-run and long-run wealth effects on consumption}

The equation to be estimated is given by

$$
\partial C_{t}=\text { const }+\alpha \partial A_{t-1}+v_{t} \text { where } v_{t} \sim N\left(0, \sigma_{v}^{2}\right)
$$

To obtain approximate marginal distributions of the one-period MPC of wealth, $\alpha$, and $\sigma_{v}^{2}$, we follow Koop (2003) or Lancaster (2004) and add the draws from the corresponding conditional posteriors to the Gibbs sampling procedure, so that step 2 from the estimation of the stickiness model is augmented by

2.4 Take a random draw ${\sigma_{v}^{2}}^{(d)}$ from $p\left(\sigma_{v}^{2} \mid \alpha^{(d-1)}\right)$

2.5 Take a random draw $\alpha^{(d)}$ from $p\left(\alpha \mid \sigma_{v}^{2^{(d)}}\right)$

To sample from $p\left(\sigma_{v}^{2} \mid \alpha\right)$, we make use of the fact that when $\alpha$ is known, the conditional distribution of $\sigma_{v}^{2}$ is inverse gamma and given by

$$
\sigma_{v}^{2} \mid \alpha \sim I G\left(\bar{T}=\underline{T}+T, \bar{\theta}=\underline{\theta}+\left(Y-\partial A_{-1} \alpha\right)^{\prime}\left(Y-\partial A_{-1} \alpha\right)\right)
$$

To sample from $p\left(\alpha \mid \sigma^{2}\right)$, we make use of the fact that when $\sigma_{v}^{2}$ is known, the conditional distribution of $\alpha$ is normal and given by

$$
\alpha \mid \sigma_{v}^{2} \sim N\left(\bar{\alpha}=\bar{V}_{\alpha}\left(\underline{V}_{\alpha}^{-1} \underline{\alpha}+\frac{1}{\sigma_{v}^{2}} \partial A_{-1}^{\prime} \partial C_{t}\right), \bar{V}_{\alpha}=\left(\underline{V}_{\alpha}^{-1}+\frac{1}{\sigma_{v}^{2}} \partial A_{-1}^{\prime} \partial A_{-1}\right)^{-1}\right)
$$

By replacing $\partial A_{-1}^{\prime} Y$ with $\partial A_{-1}^{\prime} \partial A_{-1} \alpha^{\text {ols }}$, we observed that the conditional posterior mean of $\alpha$ is a weighted average of the prior mean $\underline{\alpha}$ and the OLS estimate $\alpha^{\text {ols }}$.

Additionally, the contemporaneous MPC out of total wealth $\kappa^{i m}$ is calculated according to equation (16). Since we assume $\varepsilon$ to be serially uncorrelated, the estimates 
of $\mathcal{X}$ and $\alpha$ are independent of each other. Thus, to obtain the posterior distribution of the contemporaneous wealth effect, $p\left(\kappa^{i m} \mid \mathcal{X}, \alpha\right)$, we can just use our draws for $\mathcal{X}$ and $\alpha$ resulting from the Gibbs sampling procedure and calculate $\kappa^{i m}=\frac{\alpha}{\mathcal{X}}$ for each draw of $(\mathcal{X}, \alpha)$. We thus add the following step to sampling procedure: ${ }^{11}$

2.6 Calculate $\kappa^{i m(d)}=\frac{\alpha^{(d)}}{\mathcal{X}^{(d)}}$

Finally, the marginal posterior distribution of the long-rung wealth effect of consumption, $p(\kappa \mid \mathcal{X}, \alpha)$, follows directly from equation (22) and is obtained similarly to the posterior for the contemporaneous wealth effect, adding the following step to the sampling procedure:

2.6 Calculate $\kappa^{(d)}=\frac{\alpha^{(d)}}{\mathcal{X}^{(d)}\left(1-\mathcal{X}^{(d)}\right)}$

\footnotetext{
${ }^{11}$ The results for the marginal posterior distribution of the contemporaneous effect are not shown in the results section, but are available upon request.
} 


\section{Recent SNB Working Papers}

2016-14 Alain Galli: Sticky consumption and wealth effects in Switzerland.

2016-13 Gregor Bäurle and Rolf Scheufele: Credit cycles and real activity - the Swiss case.

2016-12 Silvio Schumacher: Networks and lending conditions: Empirical evidence from the Swiss franc money markets.

2016-11 Lucas Marc Fuhrer, Benjamin Müller and Luzian Steiner: The Liquidity Coverage Ratio and Security Prices.

2016-10 Nikola Mirkov, Igor Pozdeev and Paul Söderlind: Toward Removal of the Swiss Franc Cap: Market Expectations and Verbal Interventions.

2016-9 Severin Bernhard and Till Ebner: Cross-border Spill over Effects of Unconventional Monetary Policieson Swiss Asset Prices.

2016-8 Pinar Yeşin: Capital Flows and the Swiss Franc.

2016-7 Signe Krogstrup and Cédric Tille: On the roles of different foreign currencies in European bank lending.

2016-6 Pascal Towbin and Sebastian Weber: Price expectations and the US housing boom.

2016-5 Raphael A. Auer and Cédric Tille: The banking sector and the Swiss financial account during the financial and European debt crises.
2016-4 Christian Hepenstrick and Massimiliano Marcellino: Forecasting with Large Unbalanced Datasets: The Mixed-Frequency Three-Pass Regression Filter.

2016-3 Alain Galli: How reliable are cointegration-based estimates for wealth effects on consumption? Evidence from Switzerland.

2016-2 Pinar Yeşin: Exchange Rate Predictability and State-ofthe-Art Models.

2016-1 Sandra Hanslin and Rolf Scheufele: Foreign PMIs: A reliable indicator for exports?

2015-13 Thomas Nellen: Collateralised liquidity, two-part tariff and settlement coordination.

2015-12 Jacob Gyntelberg, Mico Loretan and Tientip Subhanij: Private information, capital flows, and exchange rates.

2015-11 Philip Sauré: Time-intensive R\&D and unbalanced trade.

2015-10 Nikola Mirkov and Andreas Steinhauer: Ben Bernanke vs. Janet Yellen: Exploring the (a)symmetry of individual and aggregate inflation expectations.

2015-9 Aleksander Berentsen, Sébastien Kraenzlin and Benjamin Müller: Exit Strategies and Trade Dynamics in Repo Markets.

2015-8 Thomas Nitschka: Is there a too-big-to-fail discount in excess returns on German banks' stocks?
From 2015, this publication series will be renamed SNB Working Papers.

All SNB Working Papers are available for download at: www.snb.ch, Research

Subscriptions or individual issues can be ordered at: Swiss National Bank

Library

P.O. Box

$\mathrm{CH}-8022$ Zurich

Phone: +41586311150

Fax: +41586315048

E-mail: library@snb.ch 
